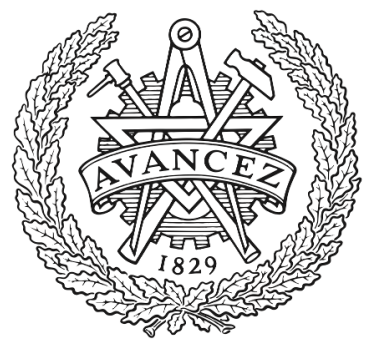

CHALMERS

UNIVERSITY OF TECHNOLOGY

\title{
Short-term creep behavior of an additive manufactured non-weldable Nickel-base superalloy evaluated by slow strain rate testing
}

Downloaded from: https://research.chalmers.se, 2023-04-26 06:42 UTC

Citation for the original published paper (version of record):

Xu, J., Gruber, H., Deng, D. et al (2019). Short-term creep behavior of an additive manufactured non-weldable Nickel-base superalloy evaluated by slow strain rate testing. Acta Materialia, 179: 142-157.

http://dx.doi.org/10.1016/j.actamat.2019.08.034

N.B. When citing this work, cite the original published paper. 
Full length article

\title{
Short-term creep behavior of an additive manufactured non-weldable Nickel-base superalloy evaluated by slow strain rate testing
}

\author{
Jinghao Xu ${ }^{a}$, Hans Gruber ${ }^{b}$, Dunyong Deng ${ }^{a}$, Ru Lin Peng ${ }^{a}$, Johan J. Moverare ${ }^{a}$, \\ ${ }^{a}$ Division of Engineering Materials, Department of Management and Engineering, Linköping University, Linköping, SE-58183, Sweden \\ b Division of Materials and Manufacture, Department of Industrial and Materials Science, Chalmers University of Technology, Gothenburg, SE-41296, \\ Sweden
}

\section{A R T I C L E I N F O}

\section{Article history:}

Received 1 July 2019

Received in revised form

18 August 2019

Accepted 19 August 2019

Available online 20 August 2019

\section{Keywords:}

Nickel-base superalloy

Laser processing

Creep

Grain boundary sliding

Dislocations

\begin{abstract}
A B S T R A C T
Additive manufacturing (AM) of high $\gamma^{\prime}$ strengthened Nickel-base superalloys, such as IN738LC, is of high interest for applications in hot section components for gas turbines. The creep property acts as the critical indicator of component performance under load at elevated temperature. However, it has been widely suggested that the suitable service condition of AM processed IN738LC is not yet fully clear. In order to evaluate the short-term creep behavior, slow strain rate tensile (SSRT) tests were performed. IN738LC bars were built by laser powder-bed-fusion (L-PBF) and then subjected to hot isostatic pressing (HIP) followed by the standard two-step heat treatment. The samples were subjected to SSRT testing at $850^{\circ} \mathrm{C}$ under strain rates of $1 \times 10^{-5} / \mathrm{s}, 1 \times 10^{-6} / \mathrm{s}$, and $1 \times 10^{-7} / \mathrm{s}$. In this research, the underlying creep deformation mechanism of AM processed IN738LC is investigated using the serial sectioning technique, electron backscatter diffraction (EBSD), transmission electron microscopy (TEM). On the creep mechanism of AM polycrystalline IN738LC, grain boundary sliding is predominant. However, due to the interlock feature of grain boundaries in AM processed IN738LC, the grain structure retains its integrity after deformation. The dislocation motion acts as the major accommodation process of grain boundary sliding. Dislocations bypass the $\gamma^{\prime}$ precipitates by Orowan looping and wavy slip. The rearrangement of screw dislocations is responsible for the formation of subgrains within the grain interior. This research elucidates the short-creep behavior of AM processed IN738LC. It also shed new light on the creep deformation mechanism of additive manufactured $\gamma^{\prime}$ strengthened polycrystalline Nickel-base superalloys.
\end{abstract}

() 2019 Acta Materialia Inc. Published by Elsevier Ltd. This is an open access article under the CC BY license (http://creativecommons.org/licenses/by/4.0/).

\section{Introduction}

Nickel-base superalloys have been one of the most important alloy systems owing to its significant role in fuel-efficient turbine engines [1]. Through the past two decades, metallic additive manufacturing (AM), also known as three-dimensional (3D) printing technique has been developed rapidly [2]. This novel process promotes localized melting and solidification of a power bed to build up a part in the manner of layer by layer. It provides advanced design flexibility for net-shaped components, e.g. turbine blades with complicated internal cooling channels. This advanced cooling configuration potentially opens up the possibility for turbine blades to operate at even higher service temperatures.

\footnotetext{
* Corresponding author

E-mail address: johan.moverare@liu.se (J.J. Moverare).
}

However, how the AM processed components can be suitably implemented in the hot-section condition requires significant consideration from both the materials science and engineering side. Since each component in a turbine engine has its own critical service environment and been adopted to the corresponding mature material systems, and the high-temperature mechanical behavior has attracted plenty of investigations on those conventionally processed Nickel-base superalloys. Among the wide family of manufacturing techniques available, different processes e.g. conventional casting [3], directional solidification [4], cast and wrought [5], and powder metallurgy [6], can be used to produce the Nickel-base superalloy components. Correspondingly, tailored compositions have been developed to improve the critical hightemperature mechanical properties.

So far, the AM community has strongly focused on weldable superalloys, such as IN718 [7], IN625 [8,9] and Hastelloy X [10], where they share the similarity that the composition of these 
superalloys have limited content of the $\gamma^{\prime}$ forming elements $\mathrm{Al}$ and Ti. Therefore, driven by more demanding applications, the investigation of non-weldable superalloys fabricated by AM is of huge interest. In order to have sufficient creep resistance, the superalloys are expected to have a high $\gamma^{\prime}$ volume fraction. Some studies related AM processes for non-weldable superalloy have been reported, which revealed the printability of those superalloys by refining the AM printing strategy [11] or tune the composition [12]. While the high-temperature mechanical properties of $\gamma^{\prime}$ containing Nickelbase superalloy processed by AM have not received much attention, the major studies are limited to the cracking susceptibility [13], powder characteristics [14], microstructures [15] or postprocess effects [16].

Among several mechanical properties, the creep resistance acts as the critical indicator of component performance under load at elevated temperatures. There were plenty of work aiming at the creep performance, creep mechanisms, and dislocation dynamics in creep of single-crystal superalloys [17-19] under constant load condition. For the $\gamma^{\prime}$ strengthened polycrystalline Nickel-base superalloy, the interaction between $\gamma^{\prime}$ and dislocation has been unveiled by characterization of substructures in depth $[20,21]$. The dislocation activity is highly dependent on the creep deformation conditions. Unocic et al. [22] found that microtwinning was the prevalent deformation mechanism of a disk superalloy ME3 applied on $677^{\circ} \mathrm{C}$ and $690 \mathrm{MPa}$ creep condition. When crept at a higher temperature $\left(760^{\circ} \mathrm{C}\right)$ and lower stress $(345 \mathrm{MPa})$, the dislocation activity revealed a distinctly different shearing configuration, which indicates partial dislocations present stacking faults with the $\gamma$ channel [23]. Instead of microtwinning and stacking fault, at hightemperature regime (above $800^{\circ} \mathrm{C}$ ) the dislocations bypass the $\gamma^{\prime}$ precipitates in a manner of thermally activated climb mechanism. Those studies majorly focus on dislocation activities, which lacks the consideration of grain microstructures. In polycrystalline materials, the grain boundaries serve as the weak points which are associated with the environmental attack (i.e. oxidation) resulting in the intergranular cracked fracture after high-temperature testing. Meanwhile, the grain boundaries of AM processed superalloy yield a zig-zag morphology [24]. These grain boundary serrations would prolong the creep life significantly [25,26]. Yet inferior creep resistance of AM processed $\gamma^{\prime}$ strengthened polycrystalline Nickel-base superalloy has been reported and claimed to be a consequence of the smaller grain size [27]. This raises the question of how the AM processed polycrystalline superalloys respond to creep deformation. Further investigation is required for a better understanding of the creep behavior of AM processed superalloy by comprehensive consideration on both grain structure and secondary precipitates.

Unfortunately, indiscriminately applying constant load creep experiments on AM processed superalloys makes little sense since the relationship between creep life, temperature and load is unknown and can be supposed to be far from that of conventionally processed superalloys. Thus, in this study, we use slow strain rate tensile test (SSRT) [28] to evaluate the creep performance of an AM superalloy at $850^{\circ} \mathrm{C}$, which is a typical operating temperature for components in turbine engines.

The outline of this study is to elucidate the high-temperature short-term creep behavior of the AM processed $\gamma^{\prime}$ strengthened Nickel-base superalloy IN738LC. Extending these studies, work has also been addressed on the tensile deformation mechanisms which are active in the plasticity and creep regime. Such studies also may shed light on the dislocation arrangement evolution during shortterm creep deformation.

\section{Experiment}

The prealloyed IN738LC powder was gas atomized under $\mathrm{Ar}$ atmosphere and supplied by Höganäs AB (Sweden). The nominal composition is given in Table 1 . The virgin state powder morphology and grain microstructure were characterized using a Hitachi SU70 field emission scanning electron microscope (FE-SEM) equipped with an Oxford EBSD detector. EBSD data analysis was performed using an open-source MATLAB toolbox MTEX [29]. For the reconstruction of grain microstructure in EBSD, all the high angle grain boundaries are defined as larger than $10^{\circ}$ misorientation. As shown in Fig. 1(a), the as-received powder has a spherical particle morphology with the diameter ranging from 5 to $80 \mu \mathrm{m}$. According to the inverse pole figure (IPF) map from EBSD measurements (Fig. 1(b)), every individual powder particle has a polycrystalline structure. Columnar dendritic structures formed during the solidification process in atomization can be observed in Fig. 1(c). Grain boundaries with different dendrite orientation on the powder particle surface are highlighted by white dotted lines. As reported by Duflos et al. [30], the cooling rate during gas atomization is up to $10^{6} \mathrm{~K} / \mathrm{s}$ to form powder particles with a diameter down to $10 \mu \mathrm{m}$. Taking the Scheil solidification freezing range $239 \mathrm{~K}$ of IN738LC (ThermoCalc, TTNi8 database) as an example, the solidification process is supposed to be accomplished within $3 \times 10^{-4} \mathrm{~s}$. Internal defects occur inside a powder particle are not surprising owing to the nature of rapid cooling. The major internal defects of the powder particles in this study are porosities, see the cross-section viewed in Fig. 1(d).

The as-received prealloyed IN738LC powder was then loaded into an EOS M290 AM printing system, equipped with a Yb fiber laser. All the test samples were built in the horizontal direction. It made the tensile bar longitudinal direction perpendicular to the building direction. As the principle directions used in this study illustrate in Fig. 2(a), the test loading direction is parallel to the powder bed build platform but perpendicular to the building direction.

After the L-PBF building process, the as-built samples were cut off from the base plate and subjected to hot isostatic pressing (HIP). The HIP has been served as an effective way to eliminate the casting defects in cast Nickel-base superalloys [31] before the development of additive manufacturing. Furthermore, for the application of AM processed components, HIP also acts as the important post-process to heal the internal defects [32], such as voids, and internal microcracks. In this study, the HIP is applied at $1210^{\circ} \mathrm{C}$ for $4 \mathrm{~h}$ accompanied by 100-200 MPa HIP pressure. Then, a standard twostep heat treatment of IN738LC follows the HIP process. The first solution heat treatment is $1120^{\circ} \mathrm{C}$ for $2 \mathrm{~h}$, then cool down to $850^{\circ} \mathrm{C}$ for $24 \mathrm{~h}$ for aging.

The microstructure of the heat treated specimen is shown in Fig. 2(b). As shown in the IPF map, the columnar grain morphology is related to the building direction, where the grain growth direction is parallel to the building direction. The IPF coloring is according to the loading direction of the test bar. In the pristine state of materials before testing, the misorientation distribution between each grain boundary (GB) is according to the inset of Fig. 2(b). The GB misorientation angle follows the axisymmetric Gaussian distribution profile, which has the mean misorientation angle to $30^{\circ}$. It should be noted that only a few misorientation angles lower than $10^{\circ}$ are present, indicating that a fully recrystallized structure is formed after HIP and HT. In addition, annealing twins are barely overserved both in the IPF map and from misorientation

Table 1

The nominal composition of IN738LC used in this study (in wt. \%).

\begin{tabular}{llllllllllll}
\hline Alloy & $\mathrm{Ni}$ & $\mathrm{Cr}$ & $\mathrm{Co}$ & $\mathrm{Mo}$ & $\mathrm{W}$ & $\mathrm{Nb}$ & $\mathrm{Al}$ & $\mathrm{Ti}$ & $\mathrm{Ta}$ & $\mathrm{C}$ & $\mathrm{B}$ \\
\hline IN738LC & Bal. & 15.7 & 8.3 & 1.8 & 2.6 & 0.9 & 3.4 & 3.3 & 1.8 & 0.11 & 0.01 \\
\hline
\end{tabular}



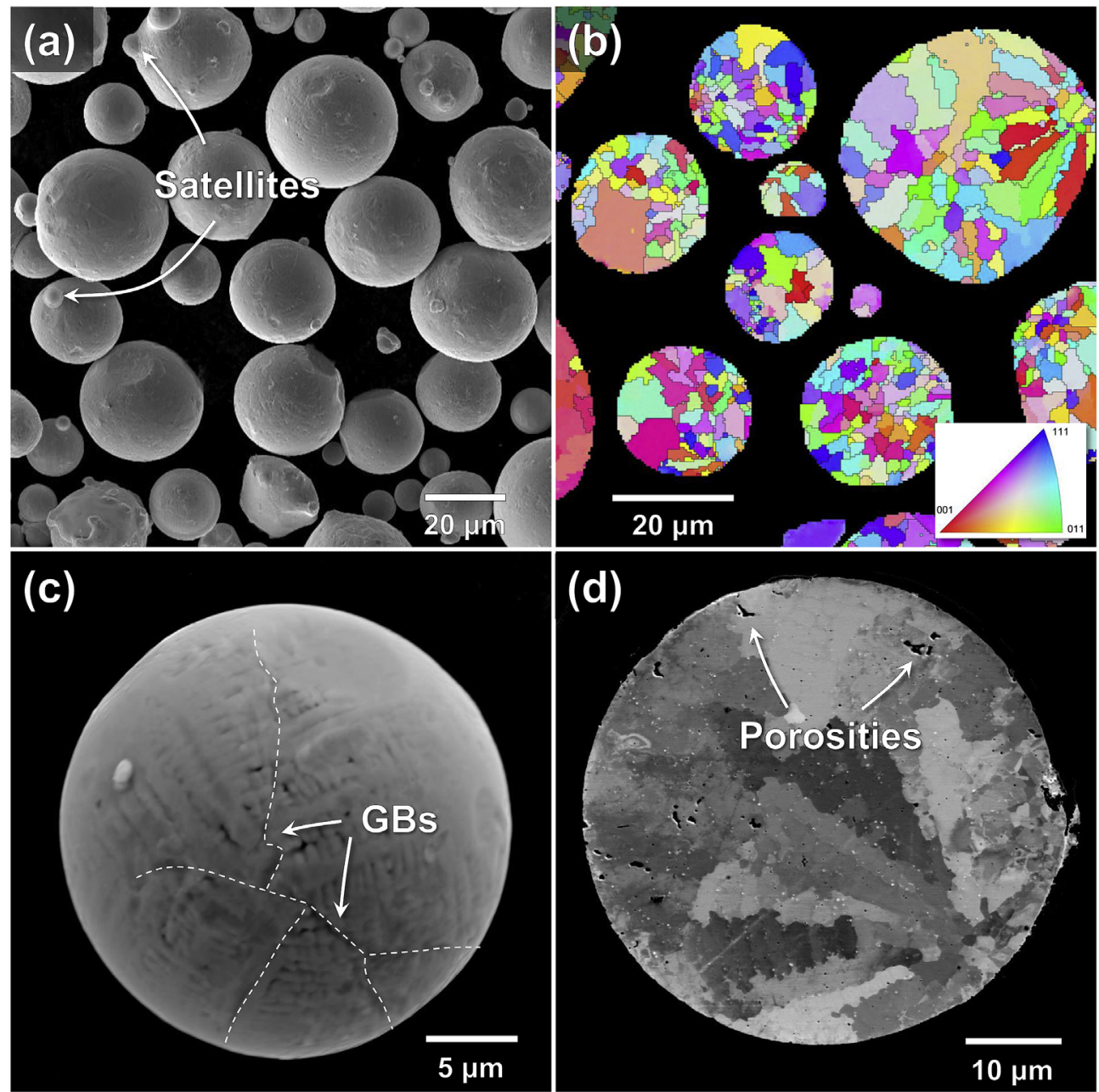

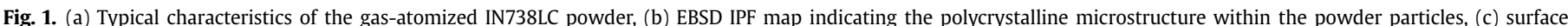
morphology of a representative powder particle, (d) SEM back-scatter micrograph illustrating the internal defects within a virgin powder particle from a cross-sectional view.

\section{distribution.}

The heat treated samples were then machined to SSRT test bars, in which the gauge diameter is $5 \mathrm{~mm}$ and the gauge length $24.5 \mathrm{~mm}$. Slow strain rate tensile tests were performed at $850^{\circ} \mathrm{C}$ in lab air under the equivalent strain rate of $10^{-5} / \mathrm{s}, 10^{-6} / \mathrm{s}$, and $10^{-7} / \mathrm{s}$, using an Instron 5982 testing system with $100 \mathrm{kN}$ load capacity. An extensometer with two ceramic rods attached the gauge length surface was used for the engineering strain measurement. The gauge length of the extensometer was $12.5 \mathrm{~mm}$.

Fractography observations were conducted using an optical microscope and SEM. Transmission electron microscopy (TEM) analysis was employed to investigate the interactions of dislocations with precipitates as well as the subgrain boundary configurations. TEM foils were cut from failure samples close to the fracture surface. Final polishing was performed using twin-jet electropolishing on a Struers apparatus. The electrolyte solution was $10 \%$ perchloric acid and $90 \%$ ethanol. The polishing temperature was $-25^{\circ} \mathrm{C}$, and polishing voltage was $20 \mathrm{~V}$. High-resolution (HR) TEM and scanning TEM (STEM) investigations were carried out on a FEI Tecnai G2 microscope operating at $200 \mathrm{kV}$ accelerating voltage.

\section{Results}

The SSRT tests are performed under isothermal test condition with a constant temperature of $850{ }^{\circ} \mathrm{C}$. The temperature change due to the deformation is negligible, which can be assessed by:

$\Delta T=\frac{\beta}{\rho C_{p}} \int_{\varepsilon_{1}}^{\varepsilon_{2}} \sigma d \varepsilon$

Where $\beta=0.9$ by assuming $90 \%$ mechanical deformation work was converted to heat, $\rho$ is the density of the specimen and $C_{p}$ is the specific heat capacity, taken as $\rho=7840 \mathrm{~kg} / \mathrm{m}^{3}$ and $C_{p}=675 \mathrm{~J} / \mathrm{k} / \mathrm{kg}$ for IN738LC superalloy at $1200 \mathrm{~K}$ [33]. As a result, the temperature rise is less than $2 \mathrm{~K}$, which can be reasonably ignored. Engineering stress-strain curves of the SSRT tests are shown in Fig. 3. Three different strain rate regimes are obviously distinguished with different yield strengths (YS), ultimate tensile strength (UTS) and tensile ductility. First, for the strength part, both the YS and UTS are affected by the strain rate, in which slowest strain rate results in most reduced YS and UTS. Second, all tests showed relativity low tensile ductility, with values less than $3 \%$. Since the tensile ductility is limited to a low value and no necking was found in the following fracture observation (Fig. 4), the strain rate is supposed to be constant beyond the elastic region. Third, the measured Young's modulus appears to have a strain-rate dependence, since Young's modulus decreases with decreasing strain rate. Since the SSRT experiments are conducted with constant displacement control, the 


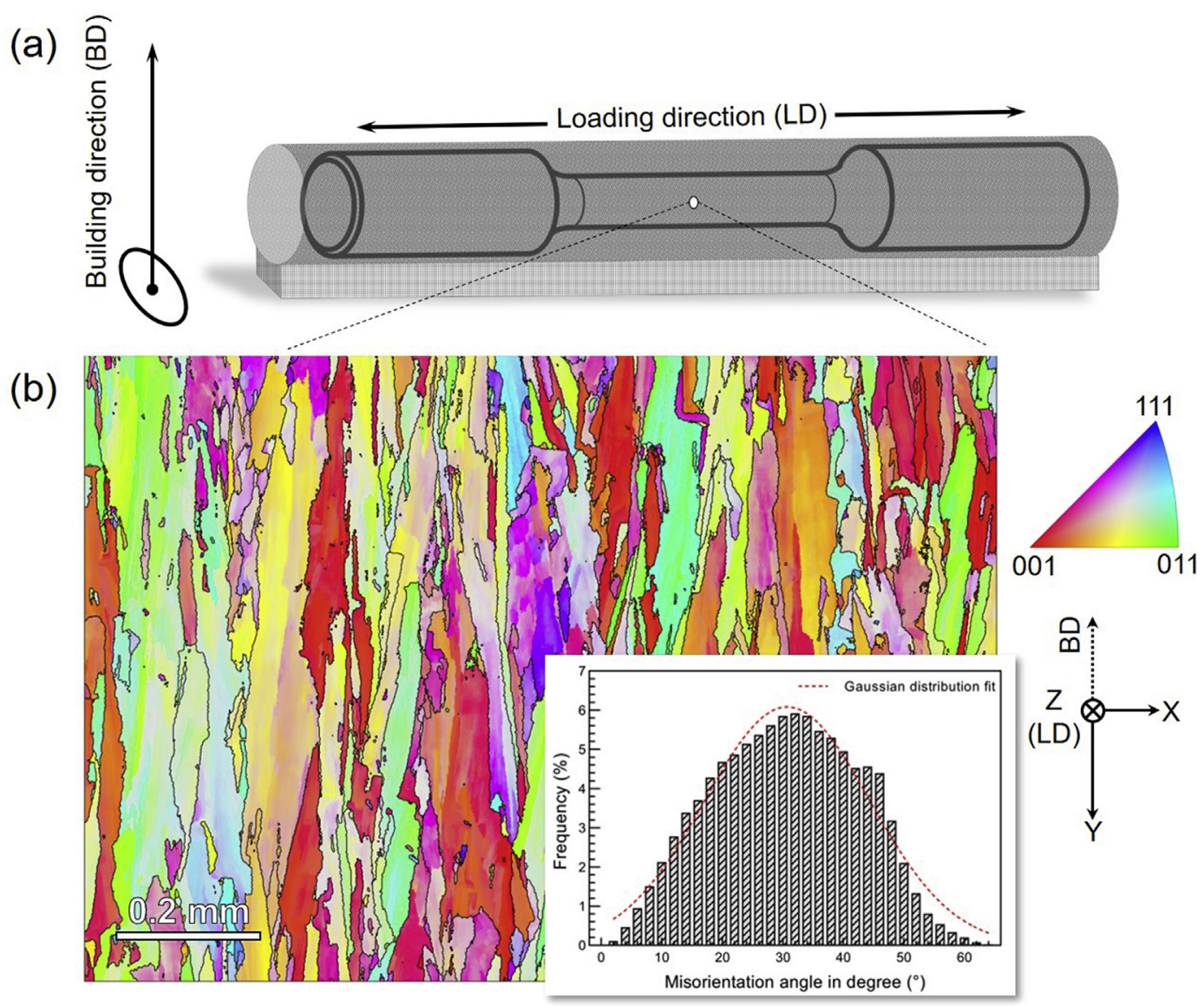

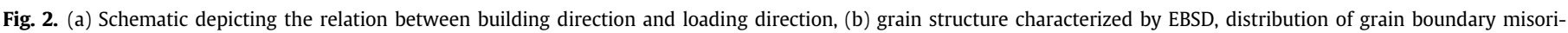
entation angles shown in the inset, IPF coloring reference axis: Z (SSRT loading direction), EBSD step size: $1 \mu \mathrm{m}$.

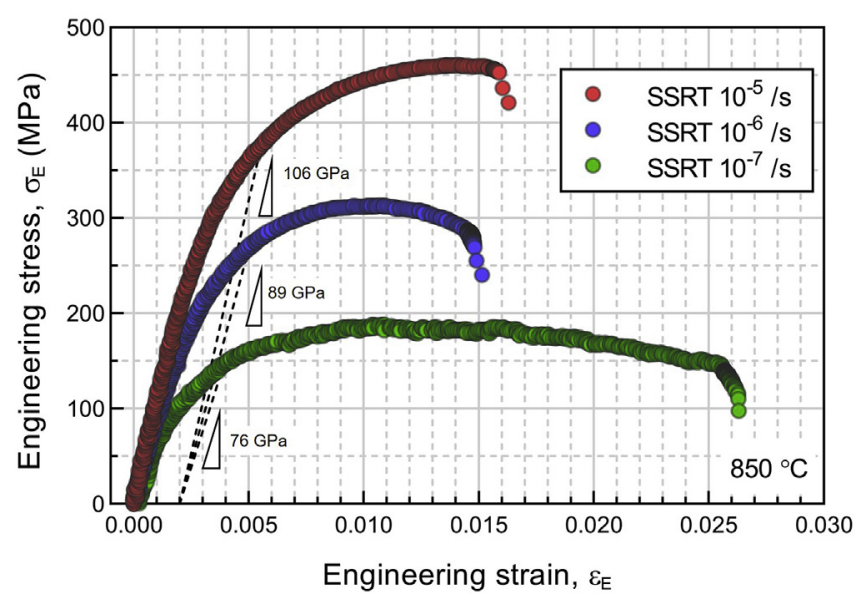

Fig. 3. Engineering stress-strain curves for $\mathrm{AM}$ processed IN738LC at $850^{\circ} \mathrm{C}$ at nominal strain rates $10^{-5} / \mathrm{s}, 10^{-6} / \mathrm{s}$, and $10^{-7} / \mathrm{s}$.

strain varies slightly during the whole tensile procedure. By calculating the strain rate at the UTS point, the creep rate can be reflected by the combination of applied stress (UTS) and strain rate (minimum strain rate at UTS). The SSRT test results are summarised in Table 2.

The fracture surfaces of the AM IN738LC superalloy after SSRT are visible in Fig. 4. All the fracture surfaces appear to have environmentally damage features, which can be seen from the darker color. Notably, the fracture surface size remained the same comparing to the as-machined test bars, indicating the absence of necking or localized necking. The red line in Fig. 4(a1), (b1) and (c1) indicate the cross-section plane cutting direction for the following characterization. The fracture surface topography is illustrated using an optical microscope Z-direction stacking. According to the fracture surface measurement in Fig. 4(a3), (b3) and (c3), a faceted grain morphology can be observed from the obvious height differences.

More fractography observations are conducted under SEM as shown in Fig. 5. It is generally believed that the dark color shown on the fracture surface is associated with an environmentally assisted damage attack during deformation. Time-dependent oxidationassisted cracking is the major environmental damage occurring in this study. Then, as shown in Fig. 5(a), the area of the environmental damage region increases as the tensile strain rate decreases. Furthermore, as shown in secondary electron imaging in Fig. 5, the intergranular cracks dominate the fracture surface for the specimens tested at $850^{\circ} \mathrm{C}$ for all the strain rates. It should be noted that, from the top view of the fracture surface, the building direction can be one of each direction parallel to the surface plane. It infers that the building direction can be deduced by the morphology of intergranular cracks, as the arrow marked in Fig. 5(b1-3). The morphology and size of the grain microstructure are consistent with the pristine state microstructure before testing. Moreover, an oxidized layer was also observed covering the decohesive grain facets, see Fig. 5(c1-3). Although the specimens have different size of the dark blue region on the fracture surface, they all show the same high-temperature intergranular fracture mechanism. 

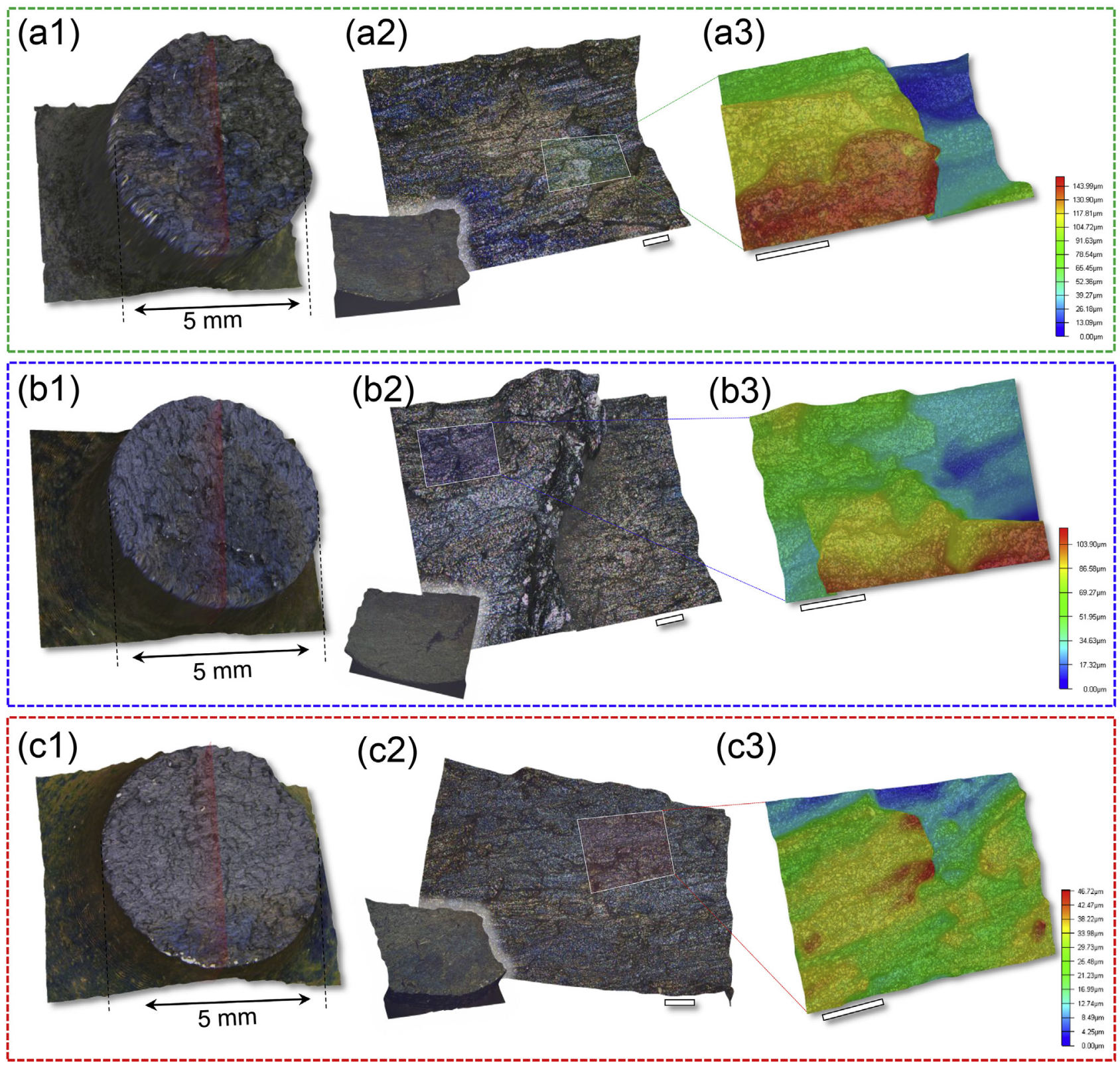

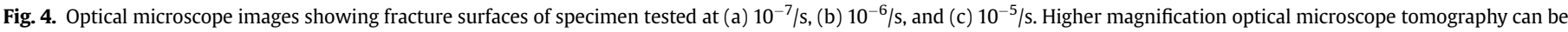
correlated to the intergranular crack features with the corresponding height contour coloring map. The scale bar, $50 \mu \mathrm{m}$.

Table 2

The SSRT results at $850^{\circ} \mathrm{C}$.

\begin{tabular}{|c|c|c|c|c|c|}
\hline Equivalent strain rate $(/ \mathrm{s})$ & YS (MPa) & UTS (MPa) & Tensile ductility (\%) & Young's modulus (GPa) & Minimum strain rate $(/ \mathrm{s})$ \\
\hline $10^{-5}$ & 376 & 460 & 1.63 & 106 & $8.0 \times 10^{-6}$ \\
\hline $10^{-6}$ & 267 & 313 & 1.51 & 89 & $8.2 \times 10^{-7}$ \\
\hline $10^{-7}$ & 148 & 188 & 2.63 & 76 & $8.3 \times 10^{-8}$ \\
\hline
\end{tabular}

Besides the fracture surface characterized by the top view, crosssectional observation reveals the interaction between grain boundaries and internal deformation defects. In general, for creep rupture occurrence, it's caused by the growth and coalescence of voids on grain boundaries. In this study, the minimum strain rates are in the range from $8.0 \times 10^{-6} / \mathrm{s}$ to $8.3 \times 10^{-8} / \mathrm{s}$, in combination with high temperature $\left(\sim 0.7 \mathrm{~T}_{\mathrm{m}}\right.$, where $\mathrm{T}_{\mathrm{m}}$ is the melting temperature in Kelvin). As shown in Fig. 6 from the back-scattered images, internal voids are frequently observed. Those voids form at grain boundaries and then coalesce to get linked with each and form microcracks. It is clear that the size of the voids is larger as the strain rate applied decreases. Cross-sectional internal defects were characterized by serial-sectioned images reconstruction. It provides a three-dimensional observation of voids and microcracks. An open-source software ImageJ [34] was used to reconstruct the image slices. It is not evident from serial sections tomography 

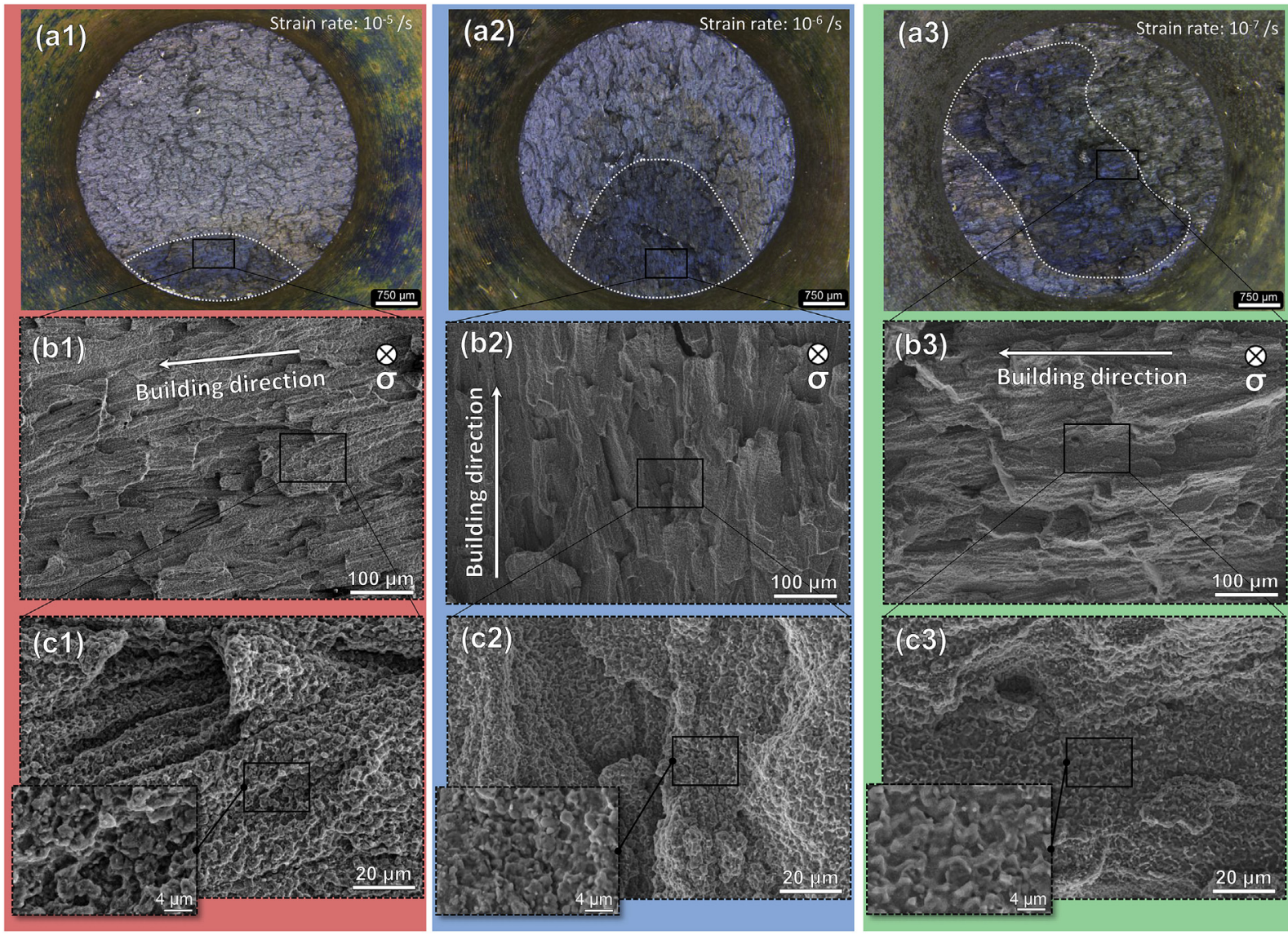

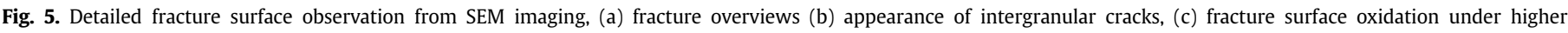
magnification SEM observations.

observations that the voids or microcracks are very localized. The voids are particularly distributed in the horizontal direction, which is transverse to the applied tensile stress (the north-south direction in Fig. 6). The morphology of those voids is observed in an olive-like shape. Basically, it is widely accepted that the void nucleation at grain boundaries is caused by condensation of vacancies under the stress [35]. After the nucleation of voids, the vacancies agglomerate and grow controlled by the micromechanics of matter transport, either by diffusion or by plasticity [36].

Of critical importance is the different strain rates applied to the IN738LC superalloy during SSRT testing, while the temperature is set constant at $850^{\circ} \mathrm{C}$. Strain rate sensitivity $(\mathrm{m})$ and flow stress activation volume $\left(V^{*}\right)$ serve as the two primary signatures of the deformation process. Thermally activated mechanisms contributing to plastic flow processes in metals can be evaluated using these two factors. The strain rate sensitivity can be expressed as the ratio of the incremental change in $\log (\sigma)$ to the resultant change in $\log (\dot{\varepsilon})$ :

$m=\frac{\partial \log (\sigma)}{\partial \log (\dot{\varepsilon})}=\frac{1}{\sigma} \cdot \frac{\partial \sigma}{\partial \ln (\dot{\varepsilon})}$

Based on Eq. (2), the strain rate sensitivity, $m$, is determined from the flow stress versus strain rate in double-log plots. From the experiment tests, $m$ is fitted to be 0.2 with $R^{2}$ (coefficient of determination) of $99.4 \%$.

The activation volume, $V^{*}$, provides significant information to distinguish different deformation mechanism, and can be expressed as [37]:
$V^{*}=\sqrt{3} k T\left(\frac{\partial \ln (\dot{\varepsilon})}{\partial \sigma}\right)$

Where $k$ is Boltzmann's constant. Substitute Eq. (2) in Eq. (3), $V^{*}$ can be calculated using the determined $m$ as:

$V^{*}=\frac{\sqrt{3} k T}{m \sigma}$

The apparent activation volume was determined to be $V^{*}=21$ $b^{3}, 30 b^{3}$, and $53 b^{3}$ for the $10^{-5} / \mathrm{s}, 10^{-6} / \mathrm{s}$, and $10^{-7} / \mathrm{s}$ tests, respective, where $b$ is the magnitude of the Burgers vector $\left(0.257 \mathrm{~nm}\right.$ at $850^{\circ} \mathrm{C}$ for Nickel-base superalloy, referenced from [38]).

By considering the grain boundaries to be the major sources and sinks for vacancies, the diffusional flow rate controlling processes can be described by Nabarro-Herring [39,40], and Coble [41] creep theories. The $\mathrm{N}-\mathrm{H}$ creep mechanism only considers the lattice diffusion rather than Coble creep for GB diffusion only. Hence, in fine grain materials, e.g. Ni with grain size down to the nanometer scale [42], the dislocation motion is reduced by the grain boundaries mobility. These two creep mechanisms are included in the diffusional creep regime and do not require dislocation motion [43]. By comparing the activation volume, it is widely accepted that diffusion mediated creep has extreme small activation volume in the order of the atomic spacing, e.g., less than $b^{3}$ [44], which is far much lower than the activation volume calculated by Eq. (4). This analysis indicates that the SSRT deformation at $850^{\circ} \mathrm{C}$ of AM processed IN738LC is not purely attributed to lattice diffusive creep or 

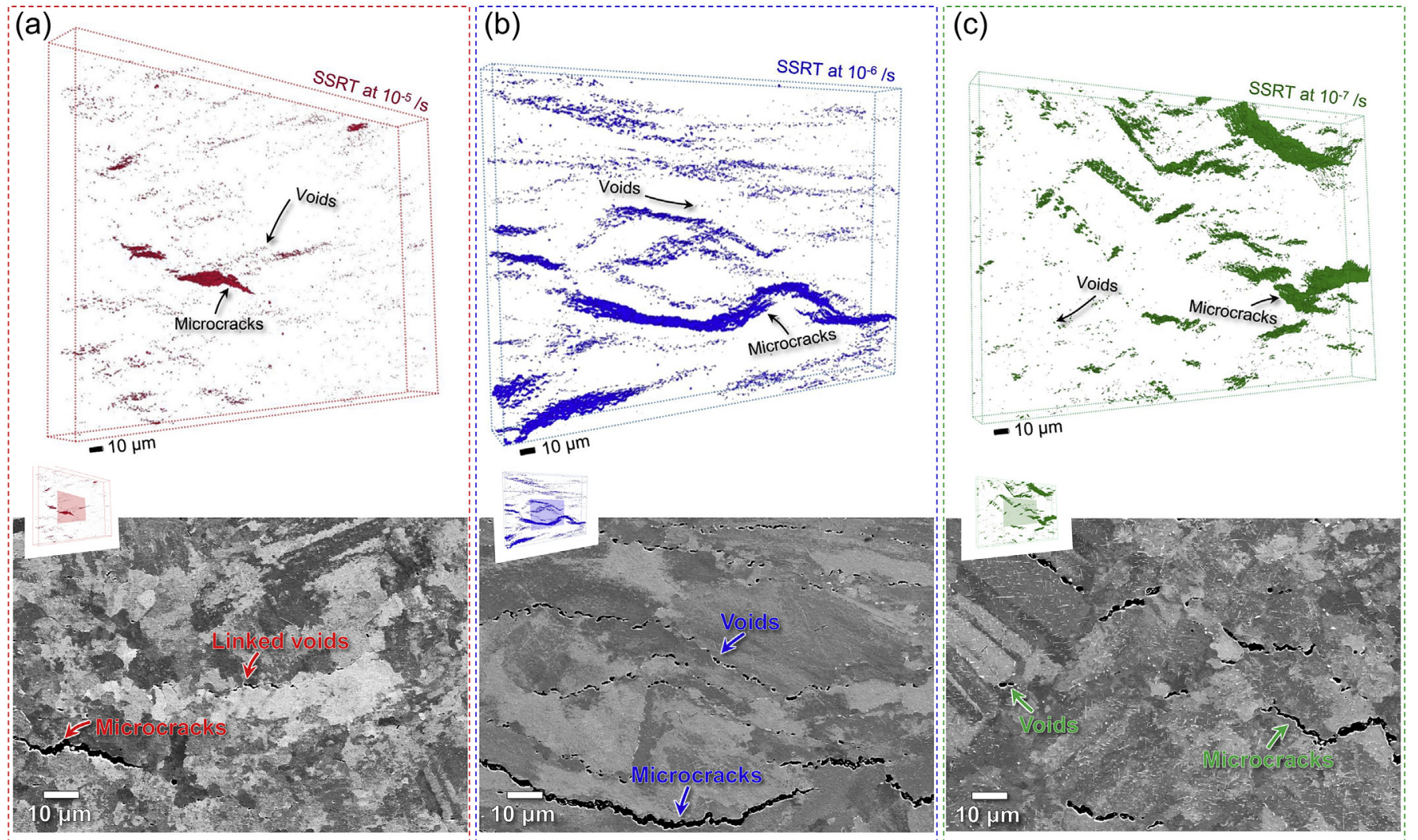

Fig. 6. Post-mortem serial-section tomography of internal deformation defects from a cross-sectional view. (a) SSRT tested at $10^{-5} / \mathrm{s},(\mathrm{b})$ at $10^{-6} / \mathrm{s}$ and (c) at $10^{-7} / \mathrm{s}$.

\section{Coble creep.}

On the other hand, larger activation volume is expected for pure dislocation-mediated plastic deformation, e.g. coarse-grained $\mathrm{Cu}$ and $\mathrm{Ni}$ leading to an activation volume of about $100-1000 \mathrm{~b}^{3}$ $[45,46]$. According to the following TEM observations in section 4.3, the interaction of dislocations played a significant role in the creep deformation, but in the intermediate-to-high temperature regime, grain boundary sliding is also activated. Considering the deformation mechanism map for IN738LC blades [47], the test results match the regime of grain boundary sliding (GBS) dominated creep mechanism.

\section{Discussion}

It is demonstrated that the L-PBF IN738LC superalloy exhibit a creep deformation behavior during slow strain rate testing at $850^{\circ} \mathrm{C}$. Intergranular cracks play a vital role in the rupture process. However, these findings require further rationalization in order to better understand the physical mechanism and the corresponding substructure response. More detailed information for understanding the deformation mechanisms can be achieved by analysis of the thermally activated deformation processes.

\subsection{Stored energy}

As the results show in Fig. 6, creep voids nucleate on grain boundaries and then act as stress concentrations. Grain boundary sliding needs be released by an accommodative mechanism in order to impede extensive void coalescence. On the grain scale, to generate good strain compatibility and low stress concentration caused by GBS, the grain structures needs to be rearranged. Recrystallization (RX) and grain-boundary migration serve as two major accommodative mechanisms to modify the grain size and grain morphology. First, the driving energy for RX is here calculated from the stored energy. Consequently, for the deformed specimens, the stored energy is approximated by considering the contribution from dislocation term and an interfacial term. Based on the EBSD characterization of the cross-section from the post-mortem samples, no deformation twins features were observed, which results in grain boundaries (GBs) as the major boundaries formed. Thus, the stored energy (E) can be expressed as [48]:

$E=E_{D}+E_{G B}$

$E_{G B}=\gamma_{G B} S_{v}$

Where $E_{D}$ is the stored energy contribution from dislocations, and $E_{G B}$ is the GB part. Then $E_{G B}$ can be expressed as GB energy per unit area of the grain boundary $\gamma_{G B}$ and the GB area per unit volume $S_{v}$ : The $\gamma_{G B}$ can be estimated using the Read-Shockley equation [49], and that the average misorientation angle $\theta$ is determined to be $30^{\circ}$ by EBSD (Fig. 2). For the high-angle grain boundary case, the empirical extension of the Read-Shockley equation by Wolf [50], substituting $\theta$ as $\sin \theta$, was used instead:

$\gamma_{G B}=\sin (\theta) \cdot \frac{1}{b} \cdot\left[E_{C}-E_{S} \cdot \ln (\sin \theta)\right]$

Where $E_{c}$ and $E_{s}$ are the dislocation-core and strain field energies, when taken dislocation core radius equals the magnitude of the Burgers vector, which can be written as: 
$E_{c}=\frac{G \cdot b^{2}}{2 \pi}$

$E_{s}=\frac{G \cdot b^{2}}{4 \pi \cdot(1-v)}($ for tilt boundaries $)$ or $E_{S}$

$=\frac{G \cdot b^{2}}{4 \pi}$ (for twist boundaries)

Where $G$ is the shear modulus and $v$ is the Poisson's ratio $(0.3)$, and it is assumed that half of the grain boundaries are tilt and half are twist. Combining these equations, $\gamma_{\mathrm{GB}}$ is calculated as $849 \mathrm{~mJ} / \mathrm{m}^{2}$, which is reasonably consistent with the reported high-angle GB energy calculated by Sangid et al. [51] for the Nickel-base superalloy U720. Moreover, the GB energy per unit volume, $E_{G B}$ is calculated to be $0.053 \mathrm{MJ} / \mathrm{m}^{3}$, by using the grain shape factor $S_{v}$ $\left(S_{v}=\frac{\pi}{2 d}\right)$, which is evaluated with grain size $\mathrm{d}=25 \mu \mathrm{m}$ (see inset in Fig. 7(a) [52].

The stored energy contribution from dislocations is positively correlated to the dislocation density, $E_{D}=\frac{1}{2} G b^{2} \rho^{g}$, where $\rho^{g}$ is the dislocation density within the grain/cell interiors. Here, we can estimate the dislocation density from Taylor's equation [53]:

$\sigma=M \alpha G b \sqrt{\rho^{g}}$

Where $M$ is the Taylor factor (3.06), $\alpha$ is an empirical constant as 0.47 for non-cell forming dislocations [54]. The $\rho^{g}$ is determined to be $9.3 \times 10^{14} / \mathrm{m}^{2}$ (calculated from the SSRT results tested at $10^{-5} / \mathrm{s}$ ), and $E_{D}$ is calculated to be $1.25 \mathrm{MJ} / \mathrm{m}^{3}$. The total stored energy is then $1.3 \mathrm{MJ} / \mathrm{m}^{3}$, compared to the barrier to the growth of a recrystallized nucleus in $\gamma^{\prime}$ containing Nickel-base superalloys, which is three orders of magnitude larger than the stored energy [55]. From both the stored energy consideration and grain size observation (Fig. 7), recrystallization has barely happened during SSRT for the tested specimens.

After deformation, the grain size in post-mortem samples have similar value compared to the samples before testing, see Fig. 7. In order to reduce the uncertainty induced by the EBSD measurement, the fine grains with grain size lower than $5 \mu \mathrm{m}$, which value is comparable to step size $1 \mu \mathrm{m}$ in this map, were excluded from the calculation. It is worth noting that the deformed grain size distribution is also in good agreement with its counterpart before testing. It supports the calculation of store energy, which indicates that dynamic recrystallization did not appear during testing in the grains larger than $5 \mu \mathrm{m}$. Thus, the mechanism of RX during SSRT testing can be ruled out for this study.

As mentioned above, grain-boundary migration is another possible mechanism for the accommodation of deformation. Despite the complex grain boundary micro-mechanism, the characteristic of migrated grain boundaries can be generally tracked by the grain boundaries morphology. The EBSD grain boundary maps are illustrated in Fig. 7(a) and (b). The AM processed superalloys in this study appear to have a serrated GB morphology. To normalize the GB morphology, the grain shape factor, $F$, can be defined as the
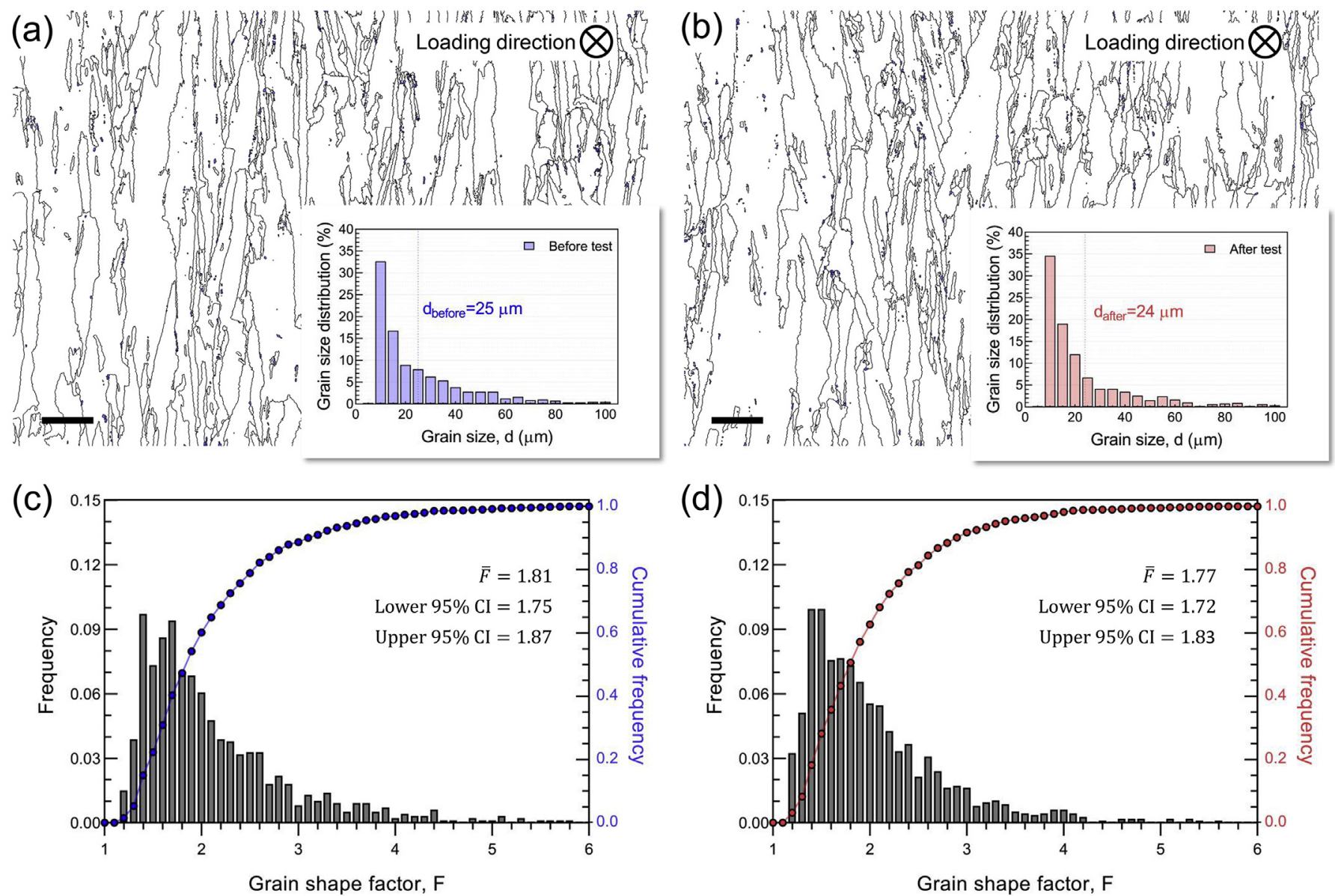

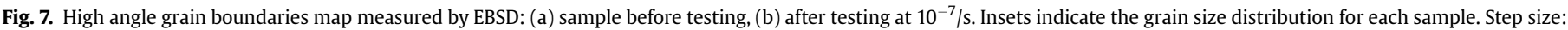
$1 \mu \mathrm{m}$, scale bar: $0.1 \mathrm{~mm}$. And grain shape factor distribution in (c) sample before testing, (d) after testing at $10^{-7} / \mathrm{s}$. 
grain boundary perimeter $P_{G B}$ divided by the equivalent perimeter $P_{E}$, as $F=\frac{P_{G B}}{P_{E}}$.

The grain shape factor distribution is shown in Fig. 7(c) and (d). The $F$ value before and after SSRT is larger than 1 , due to the serrated GBs. The mean $F$ value is 1.81 and 1.77 for the grains before and after testing, respectively, and thus very similar for the two conditions. Additionally, by comparing the post-mortem GB morphology in EBSD map with the counterpart in the pristine state, no evidence of GB migration was found. In other words, it supports that GB sliding is not accommodated by GB migration to any large degree. Although in other metallic materials system during creep, such as Titanium alloys [56], the migration of GB can be one of the most significant accommodating GB sliding, which leads to an obvious grain structure change. However, in this study, the GB migration is effectively hindered by the serration shaped GB.

\subsection{On the role of dislocation motion in SSRT deformation mechanism}

Based on the discussion in section 4.2, the grain structure of the AM processed IN738LC superalloy is stable during SSRT, giving no clear indication that recrystallization or grain boundary migration occur.

Micrographs representative of the deformation substructure after testing at $850^{\circ} \mathrm{C}$ are presented in Fig. 8. It worth mentioning that, before SSRT testing, $1210^{\circ} \mathrm{C}$ HIP was performed for $4 \mathrm{~h}$ and followed by standard heat treatment. These post-processing treatments are believed to highly reduce the dislocation density to a lower level [57,58]. We expect that the dislocations observed in Fig. 8 are responded to the SSRT deformation process. In the regime of strain rate at $10^{-5} / \mathrm{s}$, the dislocations appear in the channels between $\gamma / \gamma^{\prime}$ as in Fig. 8(a). Note that dislocation loops are left around the $\gamma^{\prime}$ particles. It shows relatively lower deformation activity than the samples after testing at $10^{-6} / \mathrm{s}$ and $10^{-7} / \mathrm{s}$. According to the substructures in Fig. 8, few shearing dislocations were found left within $\gamma^{\prime}$. When ordinary dislocations shear ordered $\gamma^{\prime}$ precipitates, they must travel in the manner of dislocation pairs to keep the order. When the size of $\gamma^{\prime}$ reaches a critical size, e.g., approximately $10-20 \mathrm{~nm}$ in planar diameter for Nickel-base superalloys, the resistance to dislocation shearing decrease. On the other hand, compared with dislocations penetrating $\gamma^{\prime}$ precipitates, the necessary stress for a dislocation to bow around these particles is lower. The required resolved shear stress for dislocation bowing was proposed by Orowan [59] as:

$\tau_{O r}=\frac{G b}{L_{S}}$

Where $L_{S}$ is the spacing between precipitates. For spherical particles, the $L_{S}$ is determined by $\gamma^{\prime}$ volume fraction and the mean planar diameter $d_{s}$ as [60]:
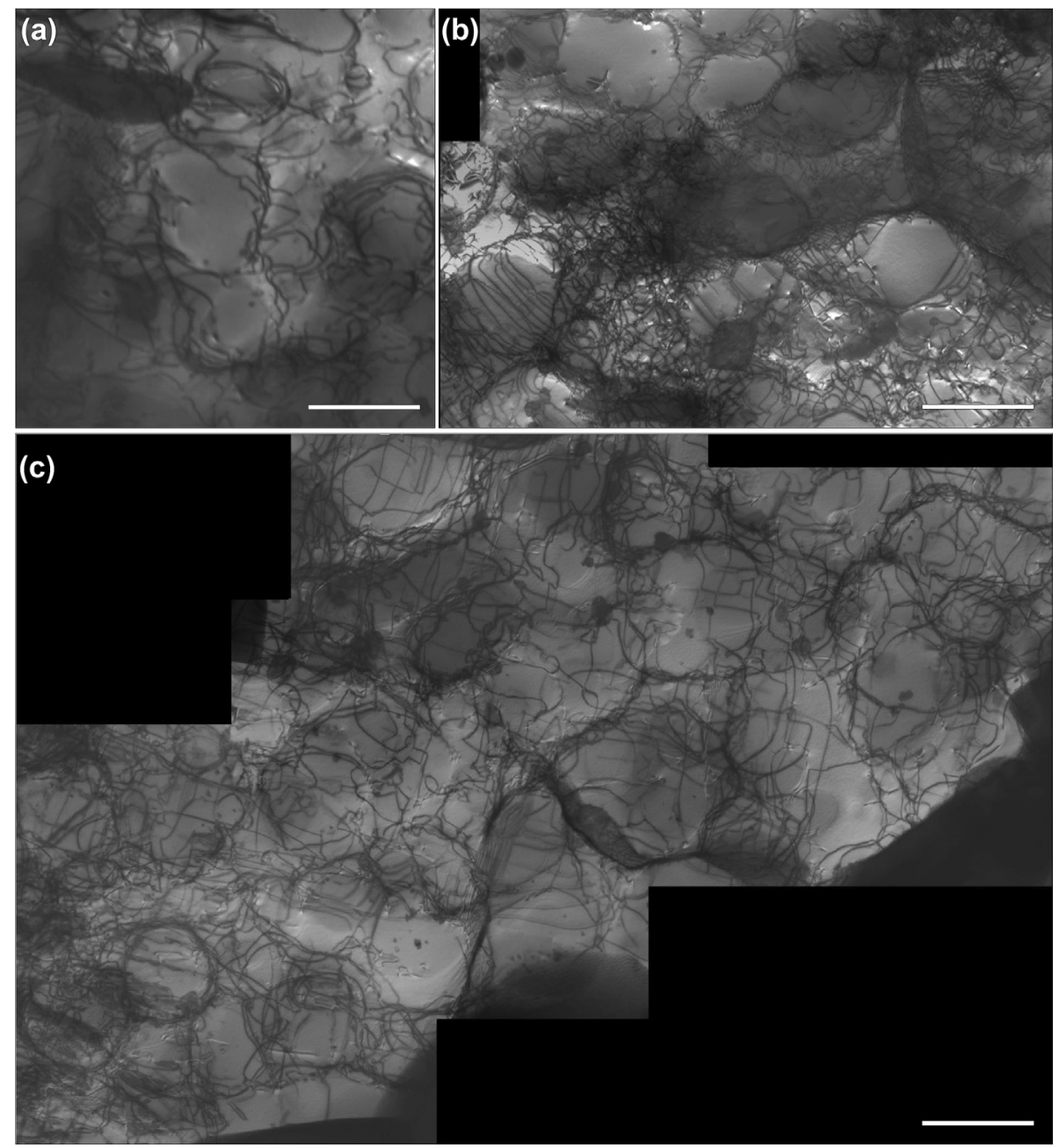

Fig. 8. BF-STEM images showing the dislocation substructure after SSRT at (a) $10^{-5} / \mathrm{s}$, (b) $10^{-6} / \mathrm{s}$, and (c) $10^{-7} / \mathrm{s}$, the scale bar is $500 \mathrm{~nm}$. 
$L_{s}=\sqrt{\frac{8}{3 \pi f}} d_{s}-d_{S}$

The volume fraction of $\gamma^{\prime}$ is determined to be $45 \%$ at $850^{\circ} \mathrm{C}$ by ThermoCalc ${ }^{\circledR}$ calculations (TCNi8 database) and the mean $\gamma^{\prime}$ diameter is estimated to be $300 \mathrm{~nm}$ based on image analysis of TEM images. It results in a value for $\tau_{O r}$ of 94,79 , and $67 \mathrm{MPa}$ for strain rates of $1 \times 10^{-5}, 1 \times 10^{-6}$, and $1 \times 10^{-7} / \mathrm{s}$, respectively. By estimating the relationship between shear stress and ultimate tensile strength (UTS) [61], the shear stress can be considered as UTS divided by Taylor's factor. It indicates that the applied uniaxial tensile stress can drive dislocation looping around $\gamma^{\prime}$ particles. It supports the dislocation configuration morphology observed in Fig. 8.

As shown in Fig. 8(b), with the strain rate decreasing to $10^{-6} / \mathrm{s}$, the dislocation density reaches the highest value among the three test conditions. The dislocation density is reflected by the plastic deformation level at this strain rate condition, but no effective dislocation recovery process is operative that resulting in the embrittlement of this sample, which is agreed with the lowest ductility in the stress-strain curves in Fig. 3. It can be found that the dislocations are highly tangled within the $\gamma$ channel. Besides the dislocation loops surrounding the $\gamma^{\prime}$ precipitates, the stair-like dislocation configuration crossing the $\gamma^{\prime}$ particles is attributed to wavy slip caused by dislocation cross slipping within the $\gamma^{\prime}$ obstacles. Similar substructures are reported for other Nickel-base superalloys crept above $700{ }^{\circ} \mathrm{C}$ [62].

For the Nickel-base superalloy strengthened by large $\gamma^{\prime}$ precipitates $(\sim 300 \mathrm{~nm})$ [60], the thermally activated cross-slip of mobile dislocations could occur. Based on the postulation of Bonneville and Escaig [63], the activation energy and activation volume for cross-slip in FCC materials can be approximated using Escaig stress model.

In short, the activation volume for cross-slip in FCC materials can be expressed as [64]:

$V^{*}=A b \lambda_{\sigma} d_{\sigma}$

Here $A$ is a constant derived as $1.55 \times \frac{\sqrt{3}}{12}, \lambda_{\sigma}$ is a typical length of the partial dislocations bending towards the constriction point under Escaig stress $\sigma_{E s c}$, and $d_{\sigma}$ is the width between the pair of dissociated partial dislocation under $\sigma_{E s c}$. Then $\lambda_{\sigma}$ and $d_{\sigma}$ can be written by multiplying the stress-related factor $\beta$ to equilibrium partial dislocation bending length $\lambda_{0}$ and equilibrium partial dissociation width $d_{0}$ as:

$\lambda_{\sigma}=\beta \lambda_{0}$ and $d_{\sigma}=\beta d_{0}$

Where:

$\beta=\left(1+\frac{\sqrt{3} b}{6 \gamma} \sigma_{E s c}\right)^{-1}$

The Escaig stress here is estimated as $\sigma_{E s c}=2 \gamma / b$ [65], here $\gamma$ is the stacking fault energy (taken as $20 \mathrm{~mJ} / \mathrm{m}^{2}$ for highly alloyed Nickel-base superalloys [66]).

$\lambda_{0}=1.5 d_{0}$

$d_{0}=\frac{G b^{2}}{24 \pi \gamma} \frac{2-3 v}{1-v}$

Then, the activation volume induced by the cross-slip is calculated to be $\sim 16 b^{3}$, which is within the same order of magnitude as the activation volume derived in section $4.1\left(V^{*} \sim 20-50 b^{3}\right)$.
This kind of dislocation configuration supports our activation volume calculation for cross-slip from substructure characterization. It has been suggested that the dislocation loop segments are driven into the narrow $\gamma$ channels and then the permeating dislocation deposit segments at the $\gamma / \gamma^{\prime}$ interfaces [67]. On the other hand, the cross-slip features can be observed from non-planar deformation bands i.e. wavy slip, which is associated with crossslipping screw dislocations. In the investigation of Phillips et al. [68] on a polycrystalline precipitation-strengthened superalloy, the wavy slip shows non-planar features which are believed to be caused by the unequal length of cross-slipping dislocations being in conjugate slip planes. The TEM images from their work [69] also provide solid evidence for the cross-slipping behavior.

Besides the Orowan loops and wavy slip lines, some subgrain boundaries are formed and can be distinguished from the array of dislocation through the continuous $\gamma$ channel at the slowest strain rate regime of $10^{-7} / \mathrm{s}$. In Fig. 8(c), the morphology, configuration and arrangement of dislocations are revealed in specimen tested under $10^{-7} / \mathrm{s}$ at $850^{\circ} \mathrm{C}$. Based on the figure, the dislocations have the following characteristics: (i) they are relatively long with the length in the scale of hundreds of nanometers; (ii) several dislocations loops appear over $\gamma^{\prime}$; (iii) jogged dislocations are formed; (iv) there is a lack of tangled dislocation; (v) there are grown-in subgrain boundaries formed through the $\gamma$ matrix channel. We discussed the effect of forming the subgrains in detailed in the next section.

\subsection{On the influence of subgrain formation on SSRT}

After testing at $10^{-6} / \mathrm{s}$, it can be seen that highly tangled dislocations have begun to form and filled the matrix channel, as shown in Fig. 9(a). Subgrains here is defined as cells consisting of wellorganized boundaries rather than tangled wall structures or dislocation networks. These square-like dislocation networks sit close to subgrain boundaries since two sets of dislocations with orthogonal Burgers vectors do not strongly react. The formation of dislocation networks can effectively cause softening, which is consistent with the lack of strain hardening behavior shown in the stress-strain curves for the specimen tested at $10^{-6} / \mathrm{s}$ and $10^{-7} / \mathrm{s}$. The rearrangement of dislocation substructures into lower-energy dislocation network configurations decrease the resistance to dislocation motion. Carroll et al. [70] also reported a similar softening behavior of a Nickel-base superalloy in the regime of creepfatigue interaction deformation.

It's an interesting comparison of the dislocation density and distribution between the substructure after testing with strain rates of $10^{-6} / \mathrm{s}$ and $10^{-7} / \mathrm{s}$. In general, the lower creep rate results in further refinement of the dislocation arrays around subgrains boundaries and a decreased dislocation density within the subgrain interiors. Moreover, subgrain boundaries also emerge. Although the dislocations underwent a rearrangement to form subgrain boundaries as shown in Fig. 9(b), the dislocation density is still relatively high in the boundary regions. A representative section of a subgrain boundary is highlighted by the white dash-line overlapped with dislocation lines marked in red in Fig. 9(b). The dislocation density along this subgrain boundary section $\rho_{S G B}$ can be estimated using the following equation introduced by Bailey and Hirsch [71] as:

$\rho_{S G B}=\frac{4}{\pi} \cdot \frac{R_{p}}{A_{r} h}$

Where $R_{p}$ is the total projected length of dislocation line in the area $A_{r}$ (the white dash-line area in Fig. 9(b)), which can be measured from STEM images and $h$ is the transparent area thickness of the TEM thin foil (taken as $50 \mathrm{~nm}$ ). The $\rho_{S G B}$ is determined to be 

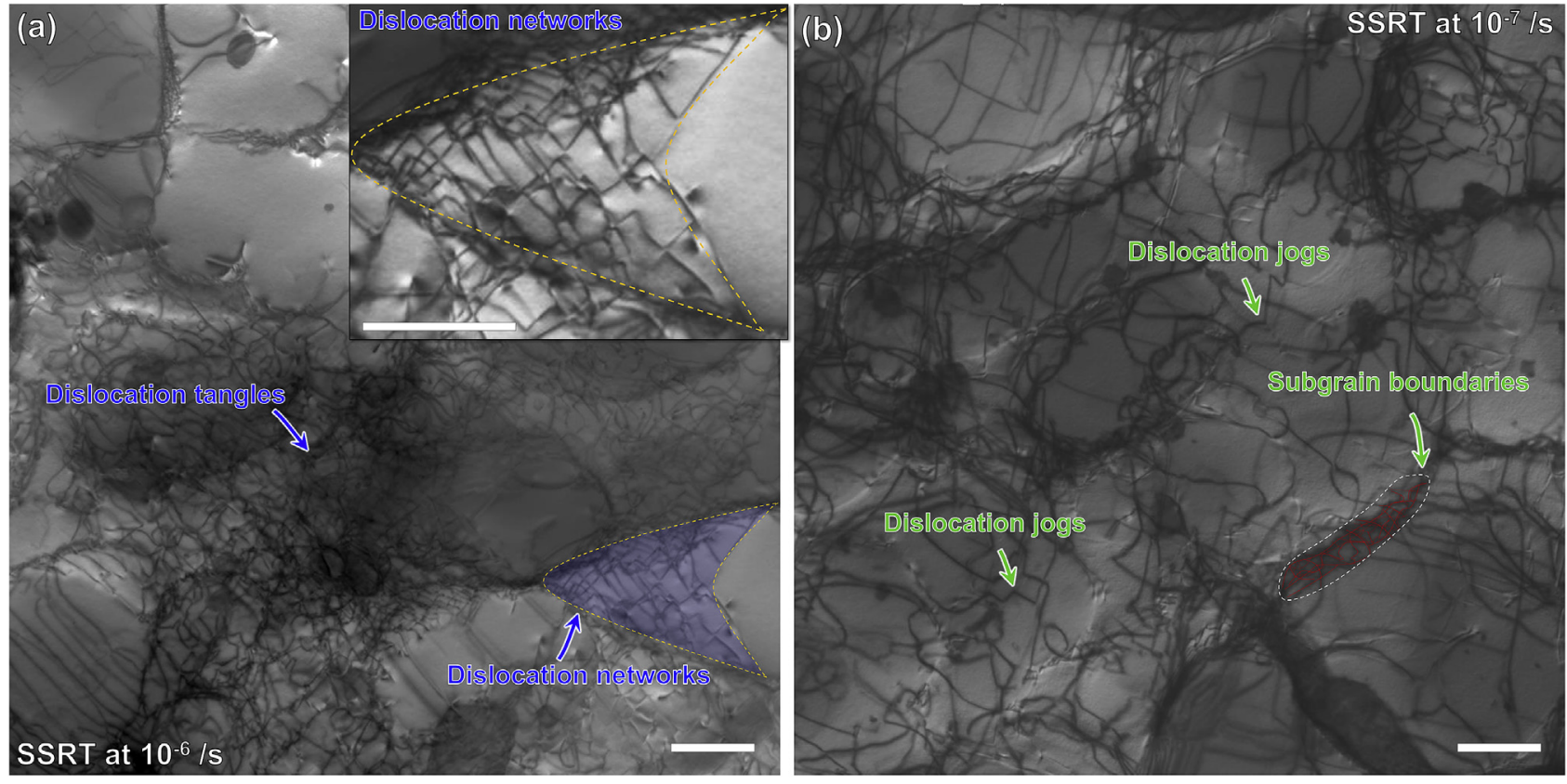

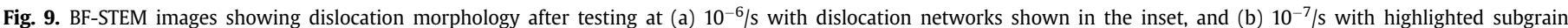
boundaries within the white dash-line. The scale bar is $200 \mathrm{~nm}$.

$2.8 \times 10^{15} / \mathrm{m}^{2}$ in this case. It indicates that the SGB region has around one order of magnitude higher density of dislocations than the dislocation density within the interior of the grains as calculated before.

These results are consistent with the experimental observation that the slowest strain rate specimen shows a strain softening behavior according to the stress-strain curve. The rearrangement of dislocation to form subgrains during the relatively longer test duration reduces the corresponding stress.

For SSRT tests with the nominal strain rate of $10^{-7} / \mathrm{s}$, the damage sites close to the fracture surface are illustrated in Fig. 10(a). As shown in Fig. 10(b), according to the IPF map of an individual grain, the crystallographic orientations vary from one location to another. The intragranular misorientation distribution within a single high angle grain boundary is shown in Fig. 10(c). Taking the mean crystallographic orientation as the reference, the intragranular misorientation angle can be expressed as:

$\operatorname{mis}\left(\boldsymbol{o}_{i}, \boldsymbol{o}_{0}\right)=\boldsymbol{o}_{i}^{-1} \boldsymbol{o}_{0}$

Where $\boldsymbol{o}_{i}$ is the crystal orientation for $i^{\text {th }}$ hit point, and $\boldsymbol{o}_{0}$ is the mean orientation from every hit point in a grain. From Fig. 10(c), one can see that the misorientation map divides into several subgrains with similar misorientation angles. Meanwhile, the orientation data is used for the local misorientations analysis to highlight subgrain boundaries. The Kernel Average Misorientation (KAM) mapping is illustrated in Fig. 10(d), in which each scan point has been assigned to a value equal to the average of the misorientation calculated between that point and its nearest 8 neighbors [72]. Different from intragranular misorientation, KAM reveals the local misorientation distribution. It clearly shows that higher KAM values are formed along the subgrain boundaries. The KAM in a subgrain interior is close to $0^{\circ}$, however at subgrain boundaries up $8^{\circ}$. It is also found in Fig. 10(d) that the interception points between subgrain boundaries and high angle grain boundaries are often consistent with the small curvature positions along the serrated grain boundaries. The KAM can be reflected as the boundaries of subgrains, where geometrically necessary dislocations (GND) are arranged in arrays. Under the assumption that the misorientation angle $\theta$ is caused by a series of twist subgrain boundaries, the GND density $\rho_{G N D}$ is related to $\theta$ as [73]:

$\rho_{G N D}=\frac{2 \theta}{u b}$

Where $u$ is the unit length of step size and $b$ is the magnitude of the Burgers vector as usual. As shown in Fig. 10(d), the first order neighbor KAM, which is calculated from the average misorientation of nearest 8 EBSD data spots, was chosen as the measure for the local misorientations. The mean KAM value of those subgrain boundaries is around $3-5^{\circ}$, from which the $\rho_{G N D}$ is approximated to be $2.0-3.4 \times 10^{15} \mathrm{~m}^{-2}$. This result is consistent with the dislocation density measured from subgrain boundaries in the BF-STEM image (Fig. 9(b)). Within a single grain, it has been suggested that subgrain boundaries with GNDs can occur from dislocation reactions to accommodate differences in slip or cross-slip. Furthermore, the morphology of the subgrains is typically elongated in one direction, which means that the growth of the subgrains is direction dependent.

Fig. 10(e) shows an example of a subgrain boundary analysis derived from the information in Fig. 10(d). In the pole figure in Fig. 10(e), three low indexed crystallographic planes $\{100\},\{110\}$ and $\{111\}$ are illustrated. The inferred subgrain boundary is oriented normal to $[00 \overline{1}]$ or parallel to $(00 \overline{1})$ plane in the example. In other FCC polycrystalline alloy systems deformed at elevated temperature, e.g. Al alloys, non-octahedral slip can happen, leading to the (001) type cube texture [74]. For SSRT in the $10^{-7} / \mathrm{s}$ regime, the movement of dislocations composes cross-slip, non-octahedral slip as well as dislocation climb, rendering the elongated subgrains.

Based on the EBSD observation of subgrain in Fig. 10, further investigation can be done in order to reveal the dislocation configurations. HR-TEM images of the subgrain boundary region are illustrated in Fig. 11. As shown in Fig. 11(a), the FCC matrix is highlighted on the upper right corner, and the subgrain boundary is 

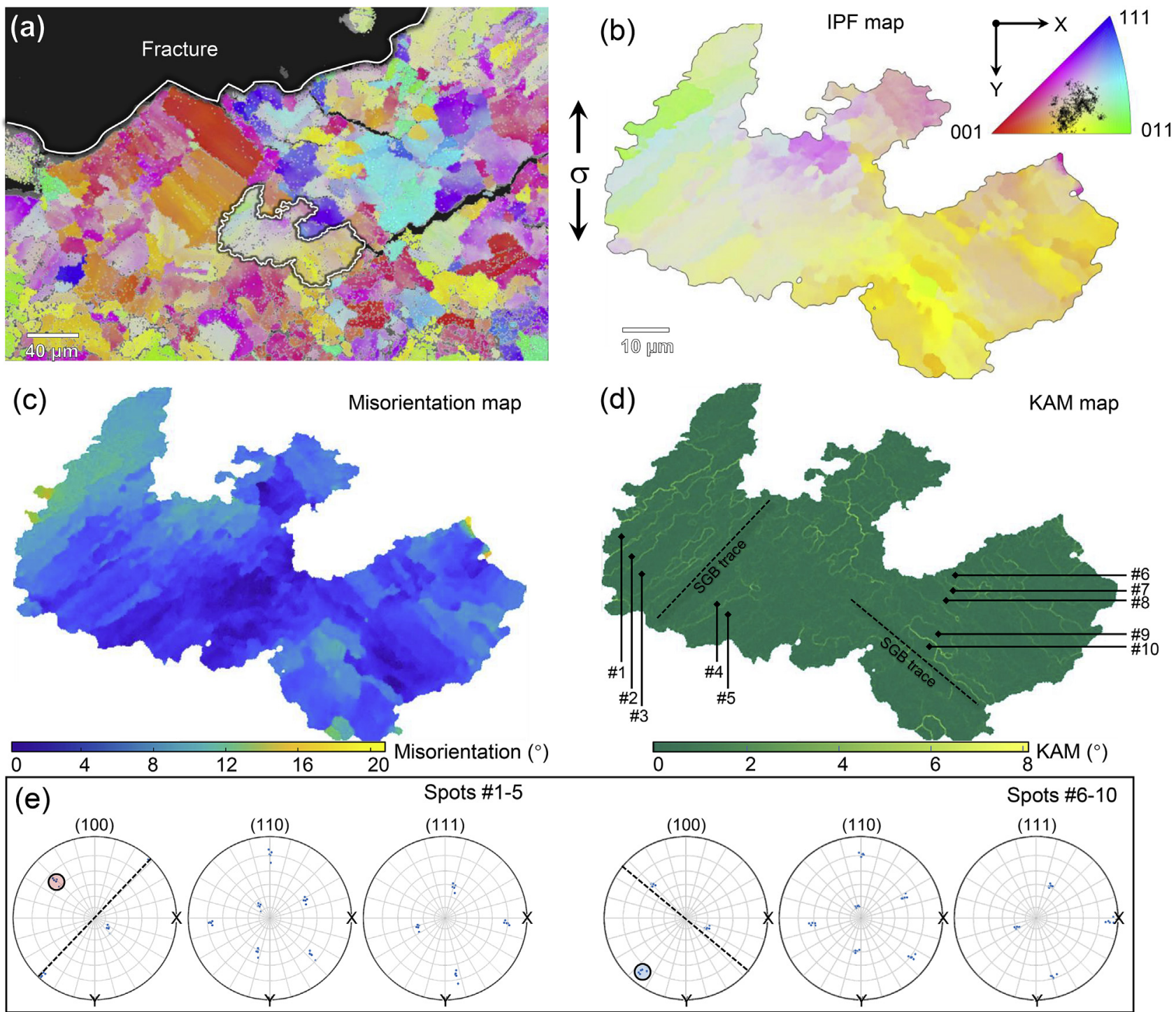

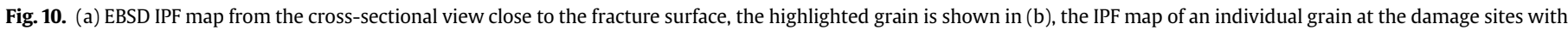

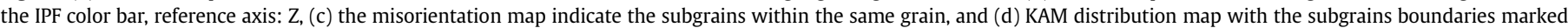

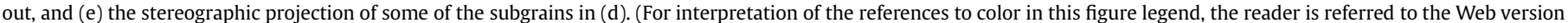
of this article.)

in the lower left region. The FCC atomic structure is shown in Fig. 11(c1), the d-spacing of (010) lattice planes is measured to be $0.35 \mathrm{~nm}$, which is consistent with the corresponding d-spacing in a Nickel matrix. The FFT pattern from the same region in Fig. 11(c1) is shown in Fig. 11(c2). It shows one set of fundamental reflections from the $\gamma$ matrix without any other reflections from the overlapping phases. For the subgrain boundary part in Fig. 11(a), the presence of washed out stripe features indicates that the periodic contrast is associated with screw dislocations. Enlarged details are shown in Fig. 11(b1) and the corresponding FFT diffraction patterns can be seen in Fig. 11(b2). The intensity of crystal planes including eight peaks along the $1.61 \mathrm{~nm}$ length is found in the inset in Fig. 11(b1) lower left corner. The d-spacing between each plane is calculated to be approximately $0.2 \mathrm{~nm}$, which is in good agreement with the d-spacing of $\{111\}$ plane in Nickel-base superalloys. The two sets of $\{111\}$ spots in Fig. 11 (b2) have a $12^{\circ}$ rotation angle caused by arrays of screw dislocations. Such an arrangement of screw dislocations leads to a change in the grain boundary angle $\theta$, between neighboring grains, as estimated by the Frank-Bilby equation [75]:

$\frac{b}{d}=2 \sin \frac{\theta}{2}$

Here $b$ is the magnitude of the Burgers vectors as usual, and $d$ is the average dislocation spacing. Based on Eq. (20), $d$ is calculated to $\sim 1.22 \mathrm{~nm}$. Here, the dislocation spacing measured from Fig. 11(d) is $1.2 \mathrm{~nm}$. Meanwhile, as schematic two arrays of rotated planes (red and blue lines) with an angle $12^{\circ}$ shown in Fig. 11(d), the black dot-lines match the position of faded screw dislocations.

To summarize, the short-term creep deformation of the AM processed IN738LC superalloy is combined with environmentallyassisted grain boundary damage and dislocation-precipitate interaction, as illustrated in Fig. 12. When the temperature reaches the high-temperature regime, this is $850^{\circ} \mathrm{C}$ in this study, grain boundary sliding (GBS) act as the most dominant deformation process. Owing to the nature of serrated grain boundaries introduced by the AM process and following post-treatment, 

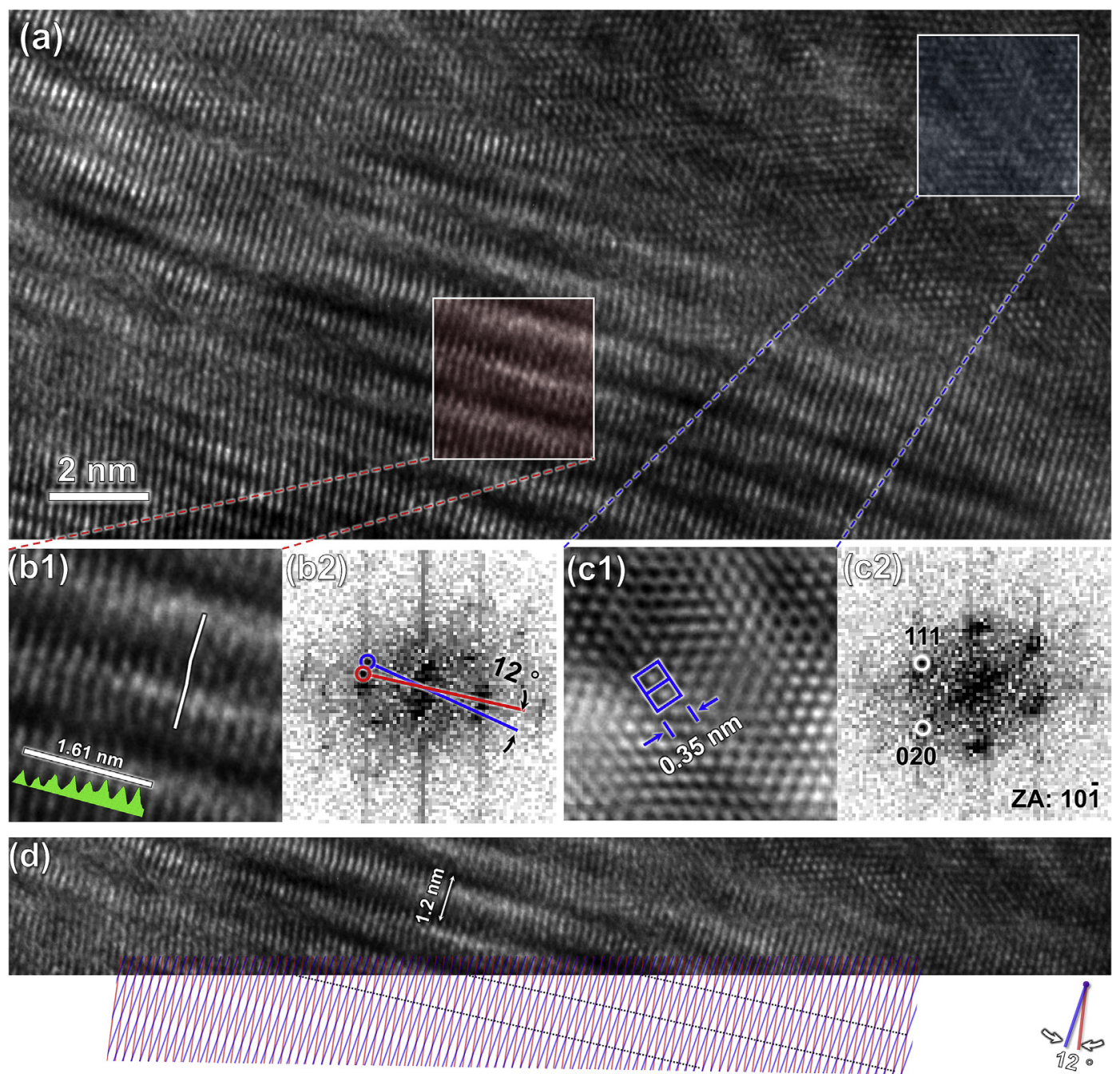

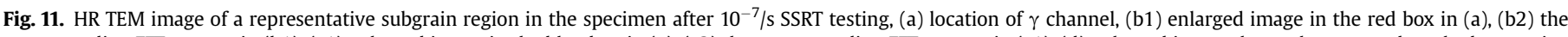

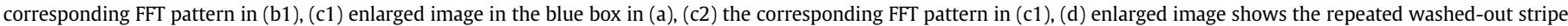
feature. Zone axis is close to $[10 \overline{1}]$. (For interpretation of the references to color in this figure legend, the reader is referred to the Web version of this article.)

intergranular voids homogeneously nucleate at GBs comparing with well-recrystallized equiaxed grain structure which has relative straight GB lines. Consequently, these intergranular voids coalesce and get linked to form microcracks which cause final failure. Thus, grain boundary sliding plays a significant role in controlling the creep deformation. In general, GBS is accommodated by the rearrangement of the grain structure, such as GB migration or even recrystallization. However, the grain boundary structures before testing remain unchanged in the post-mortem specimen which is not consistent with of GB migration. By calculating the stored energy, recrystallization can also be ruled out when comparing with the driving energy. Dislocation activities act as the operative GBS accommodation process, which is associated with the interaction between dislocations and precipitates. As a precipitate strengthened Nickel-base superalloy, the $\gamma^{\prime}$ phase provides AM processed IN738LC strength at high temperature. In this study, the dislocations loop around $\gamma^{\prime}$ phase during deforming. Dislocations also bypass $\gamma^{\prime}$ by cross slipping with the assistance of screw dislocation segments. With the deformation becoming severer, subgrain boundaries form in $\gamma$ matrix by rearrangement of arrays of dislocations in order to lower the energy from heavily tangled dislocations.

\section{Summary and conclusions}

By using the slow strain rate tensile testing approach with different strain rates corresponding to $10^{-5} / \mathrm{s}$ to $10^{-7} / \mathrm{s}$, we systematically investigated the short-term creep behavior as well as creep deformation mechanism of a laser powder-bed-fused IN738LC superalloy. The following specific conclusions can be drawn:

(i) Intergranular cracks have been observed in the AM IN738LC specimen after SSRT failure. Environmental damage during testing at $850^{\circ} \mathrm{C}$ is expected to occur along the fracture surface. As revealed by 3D reconstruction from serial section cross-sectional SEM images, the voids and microcracks along grain boundaries are greatly affected by the strain rate condition. Growth of grain boundary voids leads to microcracks and final fracture.

(ii) Grain boundary sliding is shown to be the dominant process for the creep deformation in the present study. However, the grain boundary of AM IN738LC provides stable signature which maintained its integrity after testing. The grain boundary sliding is not accommodated by the evolution of 


\section{- SSRT deformation mechanism}

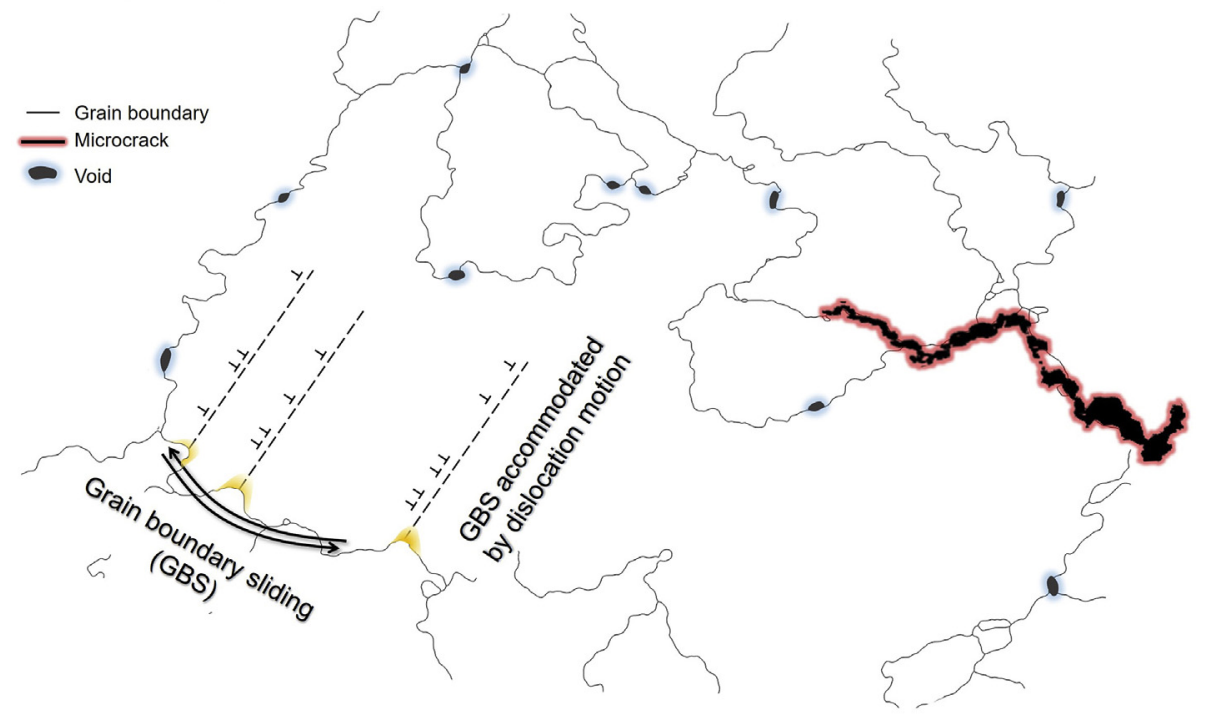

- GBS accommodation mechanism

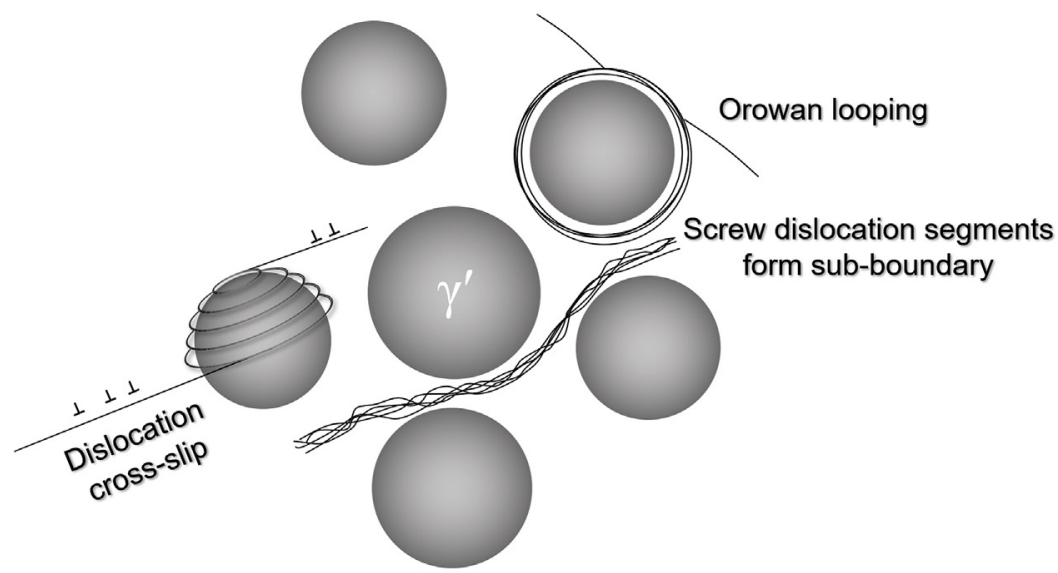

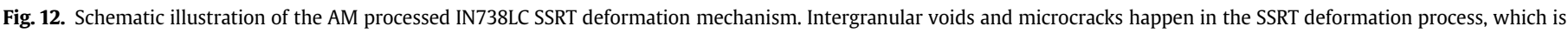

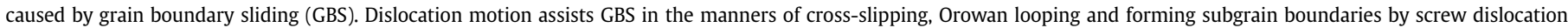
segments.

grains structure, which is convinced by both microstructure characterization and stored energy calculations.

(iii) Dislocation activity accommodates grain boundary sliding in the manner of interaction between $\gamma^{\prime}$ precipitates. By comparing the substructure observation and calculation of shear stress and activation volume, dislocations bypass $\gamma^{\prime}$ particles by Orowan looping and cross slipping.

(iv) At the slowest strain rate $10^{-7} / \mathrm{s}$ used in this study, subgrain boundary formed in the $\gamma$ channels by localized high density of dislocations up to $2.8 \times 10^{15} / \mathrm{m}^{2}$. These subgrains have a $\{011\}$ preferred orientation. These subgrain boundaries are composed of arrays of rearranged screw dislocation segments. The formation of subgrain boundaries results in the lack of work hardening.

\section{Acknowledgments}

This work has been performed with support from the Swedish Governmental Agency for Innovation Systems, (Vinnova grant 2016-05175 and 2018-00804). Also, the faculty grant SFO-MATLiU\#2009-00971 from Linköping University is acknowledged.
Centre for Additive Manufacture - Metal (CAM2) is acknowledged. The authors acknowledge Prof. E. Hryha from Chalmers University of Technology, Dr. H. Brodin from Siemens Industrial Turbomachinery $A B$, Dr. S. Bengtsson from Höganäs $A B$, Dr. A. Eklund from Quintus Technologies $A B$ and K. Minet from EOS Finland Oy for fruitful discussions. J. Xu and D. Deng acknowledge Dr. R. Boyd for TEM assistance. J. Xu acknowledges the suggestions from X. Wang of Central South University.

All data included in this study are available from the corresponding author on reasonable request.

\section{References}

[1] T.M. Pollock, S. Tin, Nickel-based superalloys for advanced turbine engines: chemistry, microstructure and properties, J. Propuls. Power 22 (2006) 361-374, https://doi.org/10.2514/1.18239.

[2] W.J. Sames, F.A. List, S. Pannala, R.R. Dehoff, S.S. Babu, The metallurgy and processing science of metal additive manufacturing, Int. Mater. Rev. 61 (2016) 315-360, https://doi.org/10.1080/09506608.2015.1116649.

[3] M.J. Starink, R.C. Thomson, The effect of high temperature exposure on dendritic segregation in a conventionally cast Ni based superalloy, J. Mater. Sci. 36 (2001) 5603-5608, https://doi.org/10.1023/A:1012513615622.

[4] M.T. Kim, S.Y. Chang, J.B. Won, Effect of HIP process on the micro-structural evolution of a nickel-based superalloy, Mater. Sci. Eng. A 441 (2006) 
126-134, https://doi.org/10.1016/j.msea.2006.09.060.

[5] L. Thébaud, P. Villechaise, C. Crozet, A. Devaux, D. Béchet, J.M. Franchet, A.L. Rouffié, M. Mills, J. Cormier, Is there an optimal grain size for creep resistance in Ni-based disk superalloys? Mater. Sci. Eng. A 716 (2018) 274-283, https://doi.org/10.1016/j.msea.2017.12.104.

[6] J. Xu, Z. Huang, L. Jiang, Low cycle fatigue behavior of a high Co polycrystalline nickel-base superalloy at $750{ }^{\circ} \mathrm{C}$, J. Alloy. Comp. 749 (2018) 1106-1114, https://doi.org/10.1016/j.jallcom.2018.03.364.

7] D. Deng J Moverare, R.L Peng H Söderberg Microstructure and anisotropic mechanical properties of EBM manufactured Inconel 718 and effects of post heat treatments, Mater. Sci. Eng. A 693 (2017) 151-163, https://doi.org/ 10.1016/j.msea.2017.03.085.

[8] A.M. Beese, Z. Wang, A.D. Stoica, D. Ma, Absence of dynamic strain aging in an additively manufactured nickel-base superalloy, Nat. Commun. 9 (2018) 2083, https://doi.org/10.1038/s41467-018-04473-5.

9] F. Zhang L.E. Levine, A.J. Allen, M.R. Stoudt, G. Lindwall, E.A. Lass, M.E. Williams, Y. Idell, C.E. Campbell, Effect of heat treatment on the microstructural evolution of a nickel-based superalloy additive-manufactured by laser powder bed fusion, Acta Mater. 152 (2018) 200-214, https://doi.org/ 10.1016/j.actamat.2018.03.017.

[10] D. Tomus, T. Jarvis, X. Wu, J. Mei, P. Rometsch, E. Herny, J.F. Rideau, S. Vaillant, Controlling the microstructure of hastelloy-X components manufactured by selective laser melting, in: Phys. Procedia, 2013, pp. 823-827, https://doi.org/ 10.1016/j.phpro.2013.03.154.

[11] S. Catchpole-Smith, N. Aboulkhair, L. Parry, C. Tuck, I.A. Ashcroft, A. Clare, Fractal scan strategies for selective laser melting of 'unweldable' nickel superalloys, Addit. Manuf. 15 (2017) 113-122, https://doi.org/10.1016/ j.addma.2017.02.002.

[12] E. Chauvet, P. Kontis, E.A. Jägle, B. Gault, D. Raabe, C. Tassin, J.-J. Blandin, R. Dendievel, B. Vayre, S. Abed, G. Martin, Hot cracking mechanism affecting a non-weldable Ni-based superalloy produced by selective electron Beam Melting, Acta Mater. 142 (2018) 82-94, https://doi.org/10.1016/ j.actamat.2017.09.047.

[13] L.N. Carter, M.M. Attallah, R.C. Reed, Laser powder bed fabrication of nickelbase superalloys: influence of parameters; characterisation, quantification and mitigation of cracking, in: Superalloys 2012, John Wiley \& Sons, Inc., Hoboken, NJ, USA, 2012, pp. 577-586, https://doi.org/10.1002/ 9781118516430.ch64.

[14] R. Engeli, T. Etter, S. Hövel, K. Wegener, Processability of different IN738LC powder batches by selective laser melting, J. Mater. Process. Technol. (2016), https://doi.org/10.1016/j.jmatprotec.2015.09.046.

[15] M. Ramsperger, R.F. Singer, C. Körner, Microstructure of the nickel-base superalloy CMSX-4 fabricated by selective electron beam melting, Metall. Mater. Trans. A 47 (2016) 1469-1480, https://doi.org/10.1007/s11661-015-3300-y.

[16] R. Muñoz-Moreno, V.D. Divya, S.L. Driver, O.M.D.M. Messé, T. Illston, S. Baker, M.A. Carpenter, H.J. Stone, Effect of heat treatment on the microstructure, texture and elastic anisotropy of the nickel-based superalloy CM247LC processed by selective laser melting, Mater. Sci. Eng. A 674 (2016) 529-539, https://doi.org/10.1016/j.msea.2016.06.075.

[17] J. Svoboda, P. Lukáš, Creep deformation modelling of superalloy single crystals, Acta Mater. 48 (2000) 2519-2528, https://doi.org/10.1016/S13596454(00)00078-1.

[18] T.M. Pollock, A.S. Argon, Creep resistance of CMSX-3 nickel base superalloy single crystals, Acta Metall. Mater. 40 (1992) 1-30, https://doi.org/10.1016/ 0956-7151(92)90195-K.

[19] C.M.F. Rae, R.C. Reed, Primary creep in single crystal superalloys: origins, mechanisms and effects, Acta Mater. 55 (2007) 1067-1081, https://doi.org/ 10.1016/j.actamat.2006.09.026.

[20] P.R. Bhowal, E.F. Wright, E.L. Raymond, Effects of cooling rate and $\gamma^{\prime}$ morphology on creep and stress-rupture properties of a powder metallurgy superalloy, Metall. Trans. A. 21 (1990) 1709-1717, https://doi.org/10.1007/ BF02672587.

[21] S. Raujol, M. Benyoucef, D. Locq, P. Caron, F. Pettinari, N. Clement, A. Coujou, Decorrelated movements of Shockley partial dislocations in the $\gamma$-phase channels of nickel-based superalloys at intermediate temperature, Philos. Mag. 86 (2006) 1189-1200, https://doi.org/10.1080/14786430500254685.

[22] R.R. Unocic, N. Zhou, L. Kovarik, C. Shen, Y. Wang, M.J. Mills, Dislocation decorrelation and relationship to deformation microtwins during creep of a $\gamma^{\prime}$ precipitate strengthened Ni-based superalloy, Acta Mater. 59 (2011) 7325-7339, https://doi.org/10.1016/j.actamat.2011.07.069.

[23] T.M. Smith, R.R. Unocic, H. Deutchman, M.J. Mills, Creep deformation mechanism mapping in nickel base disk superalloys, Mater. A. T. High. Temp. 33 (2016) 372-383, https://doi.org/10.1080/09603409.2016.1180858.

[24] Y.L. Kuo, T. Nagahari, K. Kakehi, The effect of post-processes on the microstructure and creep properties of Alloy 718 built up by selective laser melting, Materials (Basel) 11 (2018), https://doi.org/10.3390/ma11060996.

[25] A.-C. Yeh, K.-W. Lu, C.-M. Kuo, H.-Y. Bor, C.-N. Wei, Effect of serrated grain boundaries on the creep property of Inconel 718 superalloy, Mater. Sci. Eng. A 530 (2011) 525-529, https://doi.org/10.1016/j.msea.2011.10.014.

[26] Y.T. Tang, A.J. Wilkinson, R.C. Reed, Grain boundary serration in nickel-based superalloy Inconel 600: generation and effects on mechanical behavior, Metall. Mater. Trans. A (2018), https://doi.org/10.1007/s11661-018-4671-7.

[27] K. Kunze, T. Etter, J. Grässlin, V. Shklover, Texture, anisotropy in microstructure and mechanical properties of IN738LC alloy processed by selective laser melting (SLM), Mater. Sci. Eng. A 620 (2014) 213-222, https://doi.org/ 10.1016/j.msea.2014.10.003

28] M. Steen, Creep life assessment by low strain rate tensile testing, Int. J. Press Vessel. Pip. 14 (1983) 201-225, https://doi.org/10.1016/0308-0161(83) 90015-7.

[29] F. Bachmann, R. Hielscher, H. Schaeben, Texture analysis with MTEX - free and open source software toolbox, Solid State Phenom. 160 (2010) 63-68, https://doi.org/10.4028/www.scientific.net/SSP.160.63.

[30] F. Duflos, J.-F. Stohr, Comparison of the quench rates attained in gas-atomized powders and melt-spun ribbons of $\mathrm{Co}$ - and Ni-base superalloys: influence on resulting microstructures, J. Mater. Sci. 17 (1982) 3641-3652, https://doi.org 10.1007/BF00752209.

[31] M.T. Kim, S.Y. Chang, J.B. Won, Effect of HIP process on the micro-structural evolution of a nickel-based superalloy, Mater. Sci. Eng. A (2006), https:// doi.org/10.1016/j.msea.2006.09.060.

[32] L.N. Carter, C. Martin, P.J. Withers, M.M. Attallah, The influence of the lase scan strategy on grain structure and cracking behaviour in SLM powder-bed fabricated nickel superalloy, J. Alloy. Comp. 615 (2014) 338-347, https:/ doi.org/10.1016/j.jallcom.2014.06.172.

[33] P.N. Quested, R.F. Brooks, L. Chapman, R. Morrell, Y. Youssef, K.C. Mills, Measurement and estimation of thermophysical properties of nickel based superalloys, Mater. Sci. Technol. 25 (2009) 154-162, https://doi.org/10.1179/ 174328408 X361454.

[34] J. Schindelin, I. Arganda-Carreras, E. Frise, V. Kaynig, M. Longair, T. Pietzsch, S. Preibisch, C. Rueden, S. Saalfeld, B. Schmid, J.-Y. Tinevez, D.J. White, V. Hartenstein, K. Eliceiri, P. Tomancak, A. Cardona, Fiji: an open-source platform for biological-image analysis, Nat. Methods 9 (2012) 676-682, https://doi.org/10.1038/nmeth.2019.

[35] S.H. Goods, L.M. Brown, Overview NO. 1 - the nucleation OF cavities BY plastic deformation, Acta 27 (1979) 1-15, https://doi.org/10.1016/0001-6160(79) 90051-8.

[36] A.C.F. Cocks, M.F. Ashby, On creep fracture by void growth, Prog. Mater. Sci. 27 (1982) 189-244, https://doi.org/10.1016/0079-6425(82)90001-9.

[37] R.J. Asaro, S. Suresh, Mechanistic models for the activation volume and rate sensitivity in metals with nanocrystalline grains and nano-scale twins, Acta Mater. (2005), https://doi.org/10.1016/j.actamat.2005.03.047.

[38] H. Biermann, M. Strehler, H. Mughrabi, High-temperature measurements of lattice parameters and internal stresses of a creep-deformed monocrystalline nickel-base superalloy, Metall. Mater. Trans. A 27 (1996) 1003-1014, https:/ doi.org/10.1007/BF02649768.

[39] F.R.N. Nabarro, Deformation of crystals by the motion of single Lonsin report of a conference on the strength of solids, Phys. Soc. Lond. (1948) 75-90.

[40] C. Herring, Diffusional viscosity of a polycrystalline solid, J. Appl. Phys. 21 (1950) 437-445, https://doi.org/10.1063/1.1699681.

[41] R.L. Coble, A model for boundary diffusion controlled creep in polycrystalline materials, J. Appl. Phys. 34 (1963) 1679-1682, https://doi.org/10.1063/ 1.1702656 .

[42] Y. WANG, A. HAMZA, E. MA, Temperature-dependent strain rate sensitivity and activation volume of nanocrystalline Ni, Acta Mater. 54 (2006) 2715-2726, https://doi.org/10.1016/j.actamat.2006.02.013.

[43] O.D.S.J. Wadsworth, O.A. Ruano, Deformation by grain boundary sliding and slip creep versus diffusional creep, in: Miner. Met. Mater. Soc. 1999 Annu. Meet. San Diego, CA, Febr. 28-March 4, vol. 1999, 1998, pp. 425-439.

[44] X.S. Yang, Y.J. Wang, H.R. Zhai, G.Y. Wang, Y.J. Su, L.H. Dai, S. Ogata, T.Y. Zhang Time-, stress-, and temperature-dependent deformation in nanostructured copper: creep tests and simulations, J. Mech. Phys. Solids 94 (2016) 191-206, https://doi.org/10.1016/j.jmps.2016.04.021.

[45] M. Dao, L. Lu, R. Asaro, J. Dehosson, E. Ma, Toward a quantitative understanding of mechanical behavior of nanocrystalline metals, Acta Mater. 55 (2007) 4041-4065, https://doi.org/10.1016/j.actamat.2007.01.038.

[46] T. Zhu, J. Li, Ultra-strength materials, Prog. Mater. Sci. 55 (2010) 710-757, https://doi.org/10.1016/j.pmatsci.2010.04.001.

[47] S. Xu, X.J. Wu, A.K. Koul, J.I. Dickson, An intergranular creep crack growth model based on grain boundary sliding, Metall. Mater. Trans. A Phys. Metall. Mater. Sci. 30 (1999) 1039-1045, https://doi.org/10.1007/s11661-999-0156-

[48] Y.S. Li, Y. Zhang, N.R. Tao, K. Lu, Effect of the Zener-Hollomon parameter on the microstructures and mechanical properties of $\mathrm{Cu}$ subjected to plastic deformation, Acta Mater. (2009), https://doi.org/10.1016 j.actamat.2008.10.021.

[49] W.T. Read, W. Shockley, Dislocation models of crystal grain boundaries, Phys. Rev. 78 (1950) 275-289, https://doi.org/10.1103/PhysRev.78.275.

[50] D. Wolf, A read-shockley model for high-angle grain boundaries, Scr. Metall. 23 (1989) 1713-1718.

[51] M.D. Sangid, H. Sehitoglu, H.J. Maier, T. Niendorf, Grain boundary characterization and energetics of superalloys, Mater. Sci. Eng. A 527 (2010) 7115-7125, https://doi.org/10.1016/j.msea.2010.07.062.

[52] A. Godfrey, D.A. Hughes, Determination of boundary area and spacing in prismatic structures with applications to dislocation boundaries, Mater. Char (2002), https://doi.org/10.1016/S1044-5803(02)00257-7.

[53] G.I. Taylor, The mechanism of plastic deformation of crystals. Part I. Theoretical, Proc. R. Soc. A Math. Phys. Eng. Sci. 145 (1934) 362-387, https:// doi.org/10.1098/rspa.1934.0106.

[54] T. Ungár, A.D. Stoica, G. Tichy, X.L. Wang, Orientation-dependent evolution of the dislocation density in grain populations with different crystallographic orientations relative to the tensile axis in a polycrystalline aggregate of 
stainless steel, Acta Mater. 66 (2014) 251-261, https://doi.org/10.1016/ j.actamat.2013.11.012.

[55] L.H. Rettberg, T.M. Pollock, Localized recrystallization during creep in nickelbased superalloys GTD444 and Rene' N5, Acta Mater. 73 (2014) 287-297, https://doi.org/10.1016/j.actamat.2014.03.052.

[56] E. Alabort, P. Kontis, D. Barba, K. Dragnevski, R.C. Reed, On the mechanisms of superplasticity in Ti-6Al-4V, Acta Mater. 105 (2016) 449-463, https:// doi.org/10.1016/j.actamat.2015.12.003.

[57] V.D. Divya, R. Muñoz-Moreno, O.M.D.M. Messé, J.S. Barnard, S. Baker, T. Illston, H.J. Stone, Microstructure of selective laser melted CM247LC nickel-based superalloy and its evolution through heat treatment, Mater. Char. 114 (2016) 62-74, https://doi.org/10.1016/j.matchar.2016.02.004.

[58] O.M.D.M. Messé, R. Muñoz-Moreno, T. Illston, S. Baker, H.J. Stone, Metastable carbides and their impact on recrystallisation in IN738LC processed by selective laser melting, Addit. Manuf. 22 (2018) 394-404, https://doi.org/ 10.1016/j.addma.2018.05.030.

[59] M. McLean, On the threshold stress for dislocation creep in particle strengthened alloys, Acta Metall. 33 (1985) 545-556, https://doi.org/10.1016/ 0001-6160(85)90018-5.

[60] R.W. Kozar, A. Suzuki, W.W. Milligan, J.J. Schirra, M.F. Savage, T.M. Pollock Strengthening mechanisms in polycrystalline multimodal nickel-base superalloys, Metall. Mater. Trans. A 40 (2009) 1588-1603, https://doi.org/10.1007/ s11661-009-9858-5.

[61] R.E. Stoller, S.J. Zinkle, On the relationship between uniaxial yield strength and resolved shear stress in polycrystalline materials, J. Nucl. Mater. 283-287 (2000) 349-352, https://doi.org/10.1016/S0022-3115(00)00378-0.

[62] L. Cui, J. Yu, J. Liu, T. Jin, X. Sun, The creep deformation mechanisms of a newly designed nickel-base superalloy, Mater. Sci. Eng. A 710 (2018) 309-317, https://doi.org/10.1016/j.msea.2017.11.002.

[63] J. Bonneville, B. Escaig, J. Martin, A study of cross-slip activation parameters in pure copper, Acta Metall. 36 (1988) 1989-2002, https://doi.org/10.1016 0001-6160(88)90301-X.

[64] A. Malka-Markovitz, D. Mordehai, Cross-slip in face-centered cubic metals: a general Escaig stress-dependent activation energy line tension model, Philos. Mag. 98 (2018) 347-370, https://doi.org/10.1080/14786435.2017.1406194.
[65] T.S. Byun, On the stress dependence of partial dislocation separation and deformation microstructure in austenitic stainless steels, Acta Mater. 51 (2003) 3063-3071, https://doi.org/10.1016/S1359-6454(03)00117-4.

[66] M. Benyoucef, B. Décamps, A. Coujou, N. Clément, Stacking-fault energy at room temperature of the $\gamma$ matrix of the MC2 Ni-based superalloy, Philos. Mag. A 71 (1995) 907-923, https://doi.org/10.1080/01418619508236228.

[67] F. Ram, Z. Li, S. Zaefferer, S.M. Hafez Haghighat, Z. Zhu, D. Raabe, R.C. Reed, On the origin of creep dislocations in a Ni-base, single-crystal superalloy: an ECCI, EBSD, and dislocation dynamics-based study, Acta Mater. 109 (2016) 151-161, https://doi.org/10.1016/j.actamat.2016.02.038.

[68] P.J. Phillips, R.R. Unocic, M.J. Mills, Low cycle fatigue of a polycrystalline Nibased superalloy: deformation substructure analysis, Int. J. Fatigue 57 (2013) 50-57, https://doi.org/10.1016/j.ijfatigue.2012.11.008.

[69] P.J. Phillips, M.J. Mills, Fine-scale structure of dislocations and debris in deformed Ni-based superalloy R104, Philos. Mag. 93 (2013) 82-95, https:// doi.org/10.1080/14786435.2012.709949.

[70] M.C. Carroll, L.J. Carroll, Developing dislocation subgrain structures and cyclic softening during high-temperature creep-fatigue of a nickel alloy, Metall. Mater. Trans. A Phys. Metall. Mater. Sci. 44 (2013) 3592-3607, https://doi.org/ 10.1007/s11661-013-1737-4.

[71] J.E. Bailey, P.B. Hirsch, The dislocation distribution, flow stress, and stored energy in cold-worked polycrystalline silver, Philos. Mag. 5 (1960) 485-497, https://doi.org/10.1080/14786436008238300.

[72] D.P.F. Adam, J. Schwartz, Mukul Kumar, Brent L. Adams, Electron Backscatter Diffraction in Materials Science, Springer US, Boston, MA, 2009, https:// doi.org/10.1007/978-0-387-88136-2.

[73] M. Calcagnotto, D. Ponge, E. Demir, D. Raabe, Orientation gradients and geometrically necessary dislocations in ultrafine grained dual-phase steels studied by 2D and 3D EBSD, Mater. Sci. Eng. A 527 (2010) 2738-2746, https:// doi.org/10.1016/j.msea.2010.01.004.

[74] H.J. McQueen, S. Spigarelli, M.E. Kassner, E. Evangelista, Hot Deformation and Processing of Aluminum Alloys, Taylor \& Francis Group, Boca Raton, 2011.

[75] L. Wang, J. Teng, P. Liu, A. Hirata, E. Ma, Z. Zhang, M. Chen, X. Han, Grain rotation mediated by grain boundary dislocations in nanocrystalline platinum, Nat. Commun. 5 (2014) 4402, https://doi.org/10.1038/ncomms5402. 